CUAD. CONTAB. / BOGOTÁ, COLOMBIA, 16 (42): 579-623 / SEPTIEMBRE-DICIEMBRE 2015 / 59

\title{
Modelo propuesto para la detección de fraudes por parte de los auditores internos basado en las Normas Internacionales de Auditoría*
}

doi:10.11144/Javeriana.cc16-42.mpdf

José Augusto Salas-Ávila

Contador público y auditor, Universidad de Talca, Chile.

PhD en Accounting, University of Texas Pan American,

Estados Unidos. Docente titular, Escuela de Auditoría

e Ingeniería en Control de Gestión de la Universidad

de Talca, Chile. Director del Centro de Investigación y

Estudios Contables CIEC.

Correo electrónico: jsalas@utalca.cl

Nydia Marcela Reyes-Maldonado

Contadora pública, Universidad Autónoma de

Bucaramanga, UNAB, Bucaramanga, Colombia. PhD

en contabilidad y finanzas de las organizaciones,

Universidad de Zaragoza, España. Docente titular, programa contaduría pública, UNAB. Directora

grupo de Investigación en Contabilidad y Finanzas,

INVESCONFIN.

Correo electrónico: nreyes@unab.edu.co

\footnotetext{
* Artículo derivado del proyecto de convocatoria interna 2015-2016, código E56012: Diseño de un modelo pedagógico para la enseñanza de las normas de auditoría y aseguramiento de la información en un ambiente virtual de aprendizaje. Universidad Autónoma de Bucaramanga.
} 
Resumen Los auditores internos en ejercicio de sus funciones tienen la responsabilidad de detectar el fraude, aspecto que deben considerar tanto en la planeación como en la ejecución de su trabajo de auditoría. No obstante, no hay reglamentos ni normas que orienten al auditor interno para realizar esta labor de manera precisa. En efecto, esta carencia de orientación en la materia ha llevado a estudiar el efecto de las Normas Internacionales de Auditoría (NIA) aplicadas por los auditores externos sobre los procedimientos de auditoría interna. En este sentido, se procedió a diseñar un instrumento para medir las variables que afectan la detección de fraudes usando la NIA 240, Responsabilidad del auditor de considerar el fraude y error en una auditoría de estados financieros, documento del cual se utilizaron las 96 afirmaciones relacionadas con indicadores globales de riesgos de fraude en los estados financieros y de errores originados por la malversación de activos, que fueron sometidas a consideración de 617 auditores internos por medio de una encuesta que evaluaba su percepción del fraude atendiendo a estas afirmaciones. Usando un análisis factorial exploratorio y posteriormente confirmatorio (Modelo de ecuaciones estructurales, Structural Equations Model, SEM), podemos sostener con evidencia científica que, con la evaluación de solo 17 variables de las 96 previamente definidas en la NIA 240, y con un alto grado de seguridad - más de un $87 \%$ los auditores internos deberían ser capaces de minimizar la posibilidad de fraude en las empresas.

Palabras claves Detección de fraudes; Normas Internacionales de Auditoría; análisis estadístico; auditoría externa frente a auditoría interna

Códigos JEL M41, M42, M48

\section{Fraud Detection Proposed Model by Internal Auditors Based on International Standards on Auditing}

Abstract In the exercise of their duties, internal auditors are responsible for the detection of fraud, an aspect to be taken into account both into planning and at the moment of carrying out their auditing work. Still, there are no rules or regulations guiding the internal auditor at the moment of performing these duties in a precise manner. It is precisely the lack of guidance on this matter which has led us to study the effect of the International Standards on Auditing (ISA), applied by external auditors, on internal auditing procedures. In this way, we designed an instrument to measure the variables affecting fraud detection using ISA 240, The auditor's responsibilities relating to fraud in an audit of financial statements. From this document, 96 statements related with global fraud risk indicators in financial statements and errors caused by embezzlement were used and subject to assessment by 617 internal auditors using a survey which evaluates their perception of fraud, taking into account the aforementioned statements. Using exploratory, and later confirmatory, factorial analysis (Structural Equations Model, SEM), we have scientific evidence to prove that by means of the assessment of merely 17 out of 96 of the variables previously defined in the ISA 240 document -and with a degree of certainty above 87\%)- internal auditors should be able to minimize the probability of fraud in companies.

Keywords fraud detection; international standards on accounting; statistical analysis; external auditing compared to internal auditing

\section{Modelo proposto para detecção de fraude por parte dos auditores internos baseado nas Normas Internacionais de Auditoria}

Resumo Os auditores internos no exercício das suas funções são responsáveis pela detecção de fraude, aspeto a ser considerado tanto no planejamento quanto na execução do seu trabalho de auditoria. No entanto, nem tem regulamentação nem norma a orientar o auditor interno para realizar tal labor de forma precisa. De facto, tal desorientação na matéria levou a estudar o efeito das Normas 
Internacionais de Auditoria (NIA) aplicadas pelos auditores externos sobre procedimentos de auditoria interna. Neste sentido, procedeu-se a desenhar um instrumento para medir variáveis que afetam a detecção de fraudes usando a NIA 240, Responsabilidade do auditor de considerar a fraude $e$ erro em uma auditoria de demonstrações contábeis (N.T.: NBC T 11 no Brasil, Normas de Auditoria Independente das Demonstrações Contábeis, proporcionando esclarecimentos adicionais sobre a responsabilidade do auditor nas fraudes e erros, nos trabalhos de auditoria), documento do qual utilizaram as 96 afirmações relacionadas com indicadores globais de risco de fraude nas demonstrações contábeis e erros originados pela malversação de fundos, que foram submetidas à consideração de 617 auditores internos através de inquérito que avaliava a percepção da fraude atendendo a tais afirmações. Usando análise fatorial exploratória e a seguir confirmatória (Modelo de equações estruturais, Structural Equations Model, SEM), pode-se dizer com evidência científica que, com a avaliação de apenas 17 variáveis das 96 previamente definidas na NIA 240 (N.T.: NBC T 11 no Brasil) e com alto grau de segurança - mais de $87 \%$-, os auditores internos deveriam ser capazes de minimizar a possibilidade de fraude nas empresas.

Palavras-chave Detecção de fraude; Normas Internacionais de Auditoria; análise estatística; auditoria externa contra a auditoria interna

\section{Introducción}

La mayoría de los escándalos contables internacionales ocurridos tuvieron relación con fraudes financieros, e involucraron firmas auditoras y empresas conocidas en el mercado mundial, como Enron, WorldCom, Parmalat, Merck, Nortel, Global, AIG, Tyco, Xerox, Volkswagen, BMW, Boeing, entre otras, además de surgir esquemas famosos como el fraude de las niñas exploradoras (su líder Christa Utt) y nombres cono- cidos como Darryl McCauley (el comediante Dane Cook fue víctima de su medio hermano) y Bernard Madoff. En efecto, esta pérdida de confianza en las compañías les causó grandes dificultades y las que lograron sobrevivir luego del fraude ocurrido, lo hicieron gracias a que establecieron sistemas de gobierno corporativo que tuvieron un impacto positivo en los mercados de capitales y pudieron recuperar la confianza pérdida de sus inversores (Farber, 2005).

El impacto de estos fraudes no fue únicamente para las compañías afectadas, ya que lo ocurrido suscitó un amplio debate sobre el papel del auditor en la detección de fraudes y cómo en el ejercicio de su función esto debía considerarse un aspecto crucial bajo su responsabilidad. Así como los gobiernos y la profesión contable, en aras de recuperar la confianza perdida en los profesionales contables y en la información financiera, generaron normas, leyes y pronunciamientos (Ley Sarbanes-Oxley, SAS 99, NIA 240, entre otros) para definir y orientar al auditor externo respecto a su rol en la prevención y detección del fraude empresarial, incluso al punto de brindarle pautas claras sobre indicadores de fraude a tener en cuenta en la ejecución de su labor.

No obstante, en el caso de los auditores internos, no hay guías, normas o legislación específica que oriente a este auditor en la detección de fraudes, a pesar de que sí es obligación del profesional hacerlo, por lo cual se podría pensar que su actuación frente al tema queda a criterio del auditor interno. Lo anteriormente señalado hace interesante investigar cómo la ausencia de una norma de esta índole afecta el desarrollo de los procedimientos de auditoría 
interna y cómo los auditores con experiencia reaccionan ante este problema y lo afrontan en desconocimiento de la existencia de una normativa internacional que hace referencia al tema en cuestión. En efecto, esta investigación se propone estudiar cómo los auditores internos podrían usar las Normas Internacionales de Auditoría emitidas por la Federación Internacional de Contadores (IFAC), específicamente la NIA 240 Responsabilidad del auditor de considerar el fraude y error en una auditoría de estados financieros, por ser uno de los pocos referentes a los cuales podría acudir para resolver esta situación.

Sabiendo que el auditor interno tiene la responsabilidad de planificar y desarrollar la auditoría, se propone el uso de las normas internacionales clarificadas, estudiando la NIA 240 que entrega 96 variables, que deberían ser definidas y analizadas en una auditoría para dar a conocer si se está en presencia de un fraude en una empresa. El posible estudio de estas 96 variables se hace muy extenso al realizar la auditoría y contar con una lista estándar de indicios de fraude se ha asociado con una menor efectividad en la detección de un fraude (Asare \& Wright, 2004), lo que define una importante razón para realizar este trabajo de investigación, el cual busca estudiar el grado de conocimiento que poseen los auditores internos con experiencia en la detección de fraudes y definir cuáles de estas variables resultarían más importantes con base en su conocimiento en este tipo de trabajos.

En efecto, este trabajo de investigación define como su objetivo general reconocer, analizar y comparar los procedimientos aplicados por la auditoría interna relacionados con la detección de fraudes, definidos en las normas internacionales de auditoría (NIA) 240, que se aplica desde 2009 en el trabajo de auditoría externa. Específicamente, se busca lo siguiente:

- Estudiar y proyectar el efecto de la NIA 240 , relativa a la detección de fraudes, sobre la auditoría interna.

- Buscar y analizar el conocimiento de esta normativa internacional entre auditores internos.

- Adelantar los posibles efectos de la consideración de procedimientos para detectar fraudes en una auditoría interna.

- Proponer un modelo que considere las variables más importantes para la detección de fraudes que deberían aplicarse en una auditoría interna.

Hay poca claridad en los procedimientos necesarios en auditoría interna para la detección de fraudes. Adicionalmente, no hay evidencia de la factibilidad de usar procedimientos de auditoría externa en el trabajo de auditoría interna. Normalmente, en el trabajo de auditoría interna, se hace responsable al auditor por la planificación de la auditoría y la detección de fraudes. Por esta razón, los auditores internos deben guiarse por la normativa internacional que presenta en una forma más clara y detallada las consideraciones a tener en cuenta en la detección de un fraude.

Para realizar esta investigación, en primer lugar, se analizaron las responsabilidades del auditor externo frente a las del auditor interno con relación al fraude, en busca de determinar los roles similares y la viabilidad de utilizar pro- 
cedimientos de auditoría externa en una auditoría interna. Seguidamente, se indagaron los modelos de detección de fraudes propuestos en otros estudios, para entender su metodología, público objetivo y con ello, establecer el método propio de esta investigación. Una vez seleccionado el método, se diseñaron y aplicaron encuestas entre auditores internos pertenecientes a empresas reconocidas en varios países latinoamericanos y con experiencia en el trabajo de auditoría interna para identificar su percepción frente a los 96 indicios de fraude referidos en la NIA 240. Finalmente, se propone un modelo para la evaluación de factores de mayor importancia en la detección de fraudes, usando la Norma Internacional de Auditoría 240 como base teórica, aplicable al ejercicio de la auditoría interna.

En adición a lo anterior, este trabajo de investigación también busca servir de apoyo a empresas y universidades para que definan ciertos énfasis en las áreas de importancia empírica, con base en los resultados arrojados por una encuesta acerca del conocimiento que tienen los auditores internos de la normativa internacional y cómo estos afectan los procedimientos en el trabajo de auditoría relativa al fraude.

\section{Marco teórico}

En la literatura convencional de auditoría que sirve de base en el desarrollo de la formación profesional de los auditores, se define el fraude como "una falsificación de un hecho material conocido por la persona o realizado con indiferencia temeraria respecto a la veracidad, con la intención de engañar al otro y con resul- tados nocivos para este" (Whittington \& Pany, 2005, p. 91). Las Normas Internacionales para el Ejercicio Profesional de la Auditoría Interna dan otra definición de fraude como cualquier "acto ilegal caracterizado por engaño, ocultación o violación de confianza, los cuales son perpetrados por individuos y por organizaciones para obtener dinero, bienes o servicios, para evitar pagos o pérdidas de servicios, o para asegurarse ventajas personales o de negocio" (Institute of Internal Auditors, IIA, 2013).

Ninguna organización es inmune al fraude, por lo cual las empresas deben contar con un programa de prevención de riesgos de fraude que ayude a reducirlo con medidas de prevención, detección y respuesta. Hay dos tipos comunes de fraudes: informes financieros fraudulentos y malversación de activos y estos ocurren cuando hay una oportunidad percibida de cometer el acto y de ocultarlo (triángulo del fraude: poder, oportunidad y racionalización). Por lo anterior, las organizaciones deberían reducir las oportunidades de fraude por medio de la identificación y medición de los riesgos de fraude, tomando medidas para mitigar estos riesgos, al implementar y supervisar controles internos preventivos y de detección así como otras medidas disuasorias (Gonzalvo, 2003).

La responsabilidad frente al fraude es de cada organización, que desde la administración debe implementar procedimientos de control interno fuertes para este propósito. Sin embargo, los auditores deben estar en capacidad de alertar a la administración ante la presencia de indicadores de alarma o banderas rojas que, sumados a su escepticismo profesional, contribuyan a detectar un fraude en etapas tempranas 
(Malcolm, Haji-Omar, Zulkarnain-Sayd-Idris \& Baharuddin, 2005). En efecto, el rol de la auditoría interna en cuanto al riesgo de fraude está consignado en la norma 2120.A2, la cual establece que la actividad de auditoría interna debe evaluar la posibilidad de ocurrencia de fraude y cómo la organización gestiona el riesgo de fraude o, en otras palabras, debe evaluar si hay un programa de prevención de riesgos de fraude y si mitiga los riesgos para los cuales fue establecido este plan. El problema radica en que las responsabilidades están claras, pero no hay herramientas que ayuden al auditor interno a identificar posibles indicios de fraude de manera más acertada y no tan efímera como se ha venido realizando, de allí la necesidad de realizar esta investigación.

\subsection{Responsabilidades del auditor externo versus las del auditor interno frente al fraude}

Establecer responsabilidades a los auditores frente al fraude siempre ha suscitado amplio debate y sobre todo si consideramos que "durante el último siglo la función asignada al auditor frente al fraude no ha sido constante y ha sufrido grandes modificaciones" (García-Benau \& Humphrey, 1995; Villacorta-Hernández, 2014). Sin embargo, no es intención de esta investigación debatir estas responsabilidades, por lo cual se acogen aquellas que las normas internacionales de auditoría - específicamente la NIA 240-definen como tal para los auditores en relación con el fraude.

En este sentido, la auditoría financiera tiene como objetivo el análisis de los estados financieros para emitir un dictamen sobre su razonabilidad y fiabilidad. Este tipo de auditoría la realiza un auditor externo que aplica procedimientos para evaluar la razonabilidad de las cifras y si las mismas están libres de errores y fraude. Lo anterior deja claro que "la NIA 240 concede una mayor importancia a la detección de incorrecciones cuando detalla el papel del auditor como responsable de la detección del fraude y errores significativos y lo vincula a la obtención de una seguridad razonable de que los estados financieros en su conjunto estén libres de incorrecciones materiales debido a fraude o error" (Villacorta-Hernández, 2014, p. 1829).

Por otra parte, la definición de auditoría interna define como funciones del auditor interno evaluar la eficacia de los procesos de gobierno corporativo, gestión de riesgos y control. Respecto al fraude, el auditor interno debe poseer los conocimientos y habilidades suficientes que le permitan identificar indicios de fraude presentes, además de reconocer y estar alerta ante la posibilidad de que un fraude pudo haberse perpetrado, e informar a los directivos de esta situación, para que inicien una investigación más profunda. $\mathrm{Al}$ respecto, recordemos que las Normas para el Ejercicio Profesional de la Auditoría Interna del IIA sobre atributos señalan que "el auditor interno debe tener suficientes conocimientos para identificar los indicadores de fraude, pero no es de esperar que tenga conocimientos similares a los de aquellas personas cuya responsabilidad principal es la detección e investigación del fraude" (BadilloAyala, 2008; IIA, 2013).

Aquí surge una inquietud, sobre qué tan conscientes están los auditores de su rol en re- 
lación con la detección de fraudes. $\mathrm{Al}$ respecto, Todd DeZoort y Paul Harrison (2008) investigaron la percepción que los auditores internos tienen sobre su responsabilidad en la detección del fraude en cinco países. Para esto, los investigadores preguntaron a 783 auditores internos, que indicaron tener niveles moderados de responsabilidad en la detección del fraude y afirmaron que la responsabilidad recae principalmente en la administración, en los contadores y, por último, en los auditores internos. Además, los auditores internos consideran que tienen mayor responsabilidad en detectar fraudes derivados de la malversación de activos, que aquellos originados por información financiera fraudulenta o por corrupción. Esto es importante si consideramos que según la Association of Certified Fraud Examiners, ACFE (2014, p. 4), el 85\% de los casos de fraude ocurridos en su informe anual fueron de malversación de activos, "causando una pérdida promedio de US\$130.000 en contraste con el 9\% de los casos derivados de información financiera fraudulenta", aunque estos últimos fueron los más costosos (US\$1 millón en promedio). Como dato interesante, los investigadores encontraron diferencias de percepción de su responsabilidad frente al fraude según el país de procedencia, además de concluir que los auditores internos sienten que la responsabilidad de detectar fraude es más un asunto interno de la organización que algo externo.

De nuevo, la Association of Certified Fraud Examiners (ACFE, 2014) afirma en su estudio global de fraude, la importancia de que las empresas tengan controles para prevenir y detectar el riesgo de fraude; no obstante, esa asociación a su vez se planteó la inquietud de si todos los controles antifraude son iguales, o si tienen un nivel de efectividad diferente dependiendo del tipo de control. Para esto, ACFE (2014, p. 31) realizó una encuesta en la que preguntó a los participantes cuáles controles antifraude estaban presentes en la organización de la víctima en el momento en que ocurrió el fraude. Los resultados arrojaron que las auditorías externas fueron el control más común promulgado por las organizaciones víctimas de fraude, ya que estaban presentes en más del $80 \%$ de los casos reportados. No obstante, ACFE (2014) aclara que según sus resultados globales: "las auditorías externas representaron solo el 3\% de detección de casos de fraude en nuestro estudio", por lo cual concluyen que "si bien las auditorías externas sirven para muchas funciones importantes, estos resultados sugieren que no deberían tomarse como una herramienta fundamental para la detección de fraude".

En efecto, Enrique Gonzalvo (2003) y ACFE (2014) afirman que los auditores internos pueden constituirse en un medio de detección y de disuasión del fraude, incluso más efectivo que las auditorías externas; además, de acuerdo con Isa Tak, Ana Morariu y Ayhan Guney (2012), los auditores internos consideran que su labor puede mejorar la transparencia y calidad de la información financiera reportada, de allí la importancia de no desconocer el rol fundamental del auditor interno en la prevención y detección del fraude y la necesidad de dar herramientas a estos profesionales para que puedan desempeñar esta función de manera acertada. 


\subsection{Administración del riesgo de fraude por parte del auditor interno}

En el caso que nos compete, es importante recordar que tradicionalmente la auditoría interna dirigía sus esfuerzos a detectar irregularidades y fraude, aunque con el tiempo esta función cambió, pues hoy el auditor interno busca dar aseguramiento para agregar valor y mejorar las operaciones de la organización, al ampliar sus funciones más allá y quitar protagonismo a su rol tradicional frente al fraude. En este sentido, en la actualidad es responsabilidad de la administración establecer medidas para prevenir, detectar y dar respuesta al fraude, mientras que la función de la auditoría interna está en evaluar la efectividad de estas medidas, mediante el análisis de los controles establecidos, que son en últimas los que dan la oportunidad de prevenir y detectar a tiempo una situación fraudulenta en la organización. En otras palabras, "el mayor mérito atribuible a la auditoría interna debe ser su eficiencia para evitar la oportunidad y la tentación a funcionarios y empleados" y esto se logra mediante una correcta evaluación de la adecuación del sistema de control interno y su efectividad en la gestión de riesgos, incluido el riesgo de fraude (Soberanis-Aguirre de Rueda \& Herrera-Soria, 2013).

Las organizaciones suelen invertir recursos en la adecuación de un sistema de control interno efectivo, pero hay que estar conscientes de que los controles para prevenir y detectar el fraude son costosos de implementar y se hace necesario evaluar la relación costo/beneficio de los mismos. Al respecto, ACFE (2014, p. 4) encontró en su informe global de fraude que la presencia de los controles antifraude se asocia con pérdidas por fraude más reducidas y con una menor duración de fraude, por lo cual "aquellas organizaciones que implementaron cualquiera de los diversos controles antifraude más comunes, redujeron el costo de los mismos y aumentaron la velocidad de detección de los fraudes, respecto a aquellas que carecen de estos controles".

En cuanto a la oportunidad para detectar fraude, los auditores internos tienen grandes ventajas por las condiciones mismas de su labor. Por ejemplo, el aviso de los empleados respecto a la presencia de un fraude es una de las formas más comunes de detectar su ocurrencia (ACFE, 2010, 2014), tanto que en 2014, de acuerdo con el informe global de fraude de ACFE (2014, p. 4) "más del 40\% de los casos de fraude fueron detectados por un aviso de los empleados, además de representar más del doble de la tasa de descubrimientos con cualquier otro método de detección". En ese sentido, Steven E. Kaplan, Kelly Richmond-Pope y Janet A. Samuels (2011) realizaron una investigación para determinar si durante una auditoría inquisitiva, las intenciones de los empleados de reportar los fraudes conocidos variaban dependiendo del tipo de auditor, encontrando que efectivamente los empleados tienen más intención de reportar fraudes a los auditores internos que a los auditores externos.

El tamaño de la organización también puede afectar el rol del auditor para detectar fraude. Al respecto, Philmore Alleyne y Michael Howard (2005) encontraron que las grandes empresas tienden a confiar más en los controles internos y la función de detección de fraude 
recae sobre los departamentos de auditoría interna, mientras que en las empresas más pequeñas con recursos limitados, miran la auditoría externa como una auditoría equivalente a la detección de fraudes. Este hallazgo, si lo ponemos en contexto de los grandes fraudes corporativos ocurridos entre 1999 y 2002 en el mundo, enfatiza la importancia de la labor de auditoría interna frente a la evaluación de los mecanismos de control de las grandes corporaciones para prevenir y detectar el fraude.

El rol del auditor interno es claro en cuanto a la necesidad de saber identificar indicios de fraude en las organizaciones, pero también es cierto que las normas internacionales para el ejercicio profesional no ofrecen un set detallado de indicadores como sí lo hacen la SAS 99 o la NIA 240 para el caso de la auditoría externa, de allí la necesidad de buscar una alternativa que sea de aplicación para los auditores internos, que considere su percepción del fraude, que integre aspectos culturales de país y que además les sirva de guía para la planeación de su trabajo de auditoría en relación con el riesgo de fraude.

\subsection{NIA 240 y la detección de fraudes en una auditoría interna}

La NIA 240 requiere que el auditor evalúe el riesgo de afirmaciones erróneas significativas derivadas de fraude en los estados financieros y derivadas de fraude por la omisión de los controles por parte de la gerencia. Al respecto de esto último, la NIA 240 alienta a los auditores a evaluar de manera importante el control interno, pues el estándar señala explícitamente que una oportunidad clara de fraude se puede presentar cuando una persona de la organiza- ción percibe que el control interno se puede sobrepasar, ya sea porque está en una posición de poder, o porque tiene conocimiento sobre debilidades específicas del mismo, aspectos que facilitarían la perpetración de un fraude en la organización (IAASB, 2009).

En este sentido, en el apéndice de la NIA 240 se define un set de variables para la detección de fraudes en el trabajo de auditoría externa y en vista de que en las Normas Internacionales para el ejercicio profesional de la auditoría interna no hay un set de variables tan detallado como el mencionado anteriormente, no se ve ningún inconveniente en que los auditores internos tengan en cuenta las variables de la NIA 240 en la ejecución de su labor. Además, en este set de variables se incluyen varios aspectos relacionados con el control interno, tanto en fraudes por malversación de activos, como en fraudes por presentación de información financiera fraudulenta, lo cual hace válido su uso en auditoría interna. Además, Leopoldo Isaac Gurovich (2006, p. 34) señala que un aspecto importante mencionado por la NIA 240 es que al obtener la comprensión de la entidad y su entorno, incluyendo su control interno, el auditor debe considerar si la información obtenida indica que hay uno o más "factores de riesgo de fraude", por lo cual el papel del auditor interno es fundamental, ya que como afirma Gurovich (2006, p. 34), "un ambiente de control ineficaz puede generar una oportunidad para cometer fraude" y aunque esto no necesariamente es un indicador de la existencia de fraude, estos factores suelen estar presentes en circunstancias en las que efectivamente se ha producido un fraude. 
En esta misma línea de ideas, no se puede desconocer la importancia de la función de la auditoría interna en la detección de fraudes, ya que las organizaciones que cuentan con esta son más propensas a detectar los fraudes, que aquellas compañías que no tienen esta función o que la misma es ejercida por medio de la externalización de servicios (Coram, Ferguson \& Moroney, 2008). En consecuencia, generar una herramienta que ayude a los auditores internos a detectar la posible presencia de fraude en una organización, se vuelve algo de suma importancia, pues al facilitarles esta labor, se contribuiría a disminuir los impactos que un fraude no detectado a tiempo trae tanto a las empresas, como a la imagen de los auditores.

\subsection{Modelos existentes para detectar}

\section{fraude en una auditoría}

En el hilo de esta búsqueda y en aras de generar un modelo de detección de fraudes para auditores internos, es necesario indagar qué metodologías han sido usadas para este propósito o similares y si la intención de usar la NIA 240 y sus indicadores de fraude es consecuente, posible y aplicable para un modelo de estas características.

Respecto a lo anterior, Glen David Moyes (1991) realizó en su tesis doctoral una investigación para determinar el grado de efectividad de 218 técnicas de auditoría para detectar el fraude, contenidas en los Statement Auditing Standards - SAS - 53, 54, 55 en relación con las diferencias percibidas por tres grupos distintos de auditores, para lo cual realizó un cuestionario de escala Likert y encontró que 46 variables específicas fueron valoradas como las más efectivas al detectar fraudes; adicionalmente, el autor detectó diferencias significativas en la percepción de los grupos de auditores externos sometidos al estudio, pero en tan solo 6 técnicas de auditoría muy específicas, por lo cual se apreció un consenso entre los auditores en relación con el fraude.

Por otra parte, Stephen Owusu-Ansah, Glen David Moyes, Peter Babangida Oyelere y David Hay (2002) realizaron una investigación para determinar si 56 procedimientos estándar de auditoría para detección de fraudes en el ciclo de almacén eran percibidos por los auditores externos de Nueva Zelanda como efectivos, para lo cual enviaron un correo electrónico con una encuesta de escala Likert que recogiera su opinión. Sus resultados arrojaron que 14 de las 56 variables eran más significativas.

Los estudios anteriores correponden a sets de indicadores antes de la ocurrencia de la mayoría de los escándalos corporativos, por lo cual es importante tener en cuenta que a partir de 2002, se inició en el mundo la emisión de leyes, normas y pronunciamientos relativos al tema teniendo en cuenta las desafortunadas situaciones de fraude ocurridas (Ley Sarbanes-Oxley y SAS 99, entre otros). Al respecto, Michael J. Ramos (2003) menciona que el que Instituto Americano de Contadores Públicos Certificados (AICPA) emitió la SAS 99, Consideration of Fraud in a Financial Statement Audit, en vista de los escándalos corporativos que afectaron la confianza de los inversores en los mercados de capitales, en un intento por restablecer la imagen deteriorada de los auditores por esta situación. El objetivo del estándar fue proveer a los auditores de una guía de actuación frente al 
fraude financiero empresarial. Para lo anterior, el estándar lista una serie de factores ilustrativos de riesgo de fraude con el ánimo de ayudar al auditor en la ejecución de su trabajo, con la particularidad de que esos factores están listados siguiendo la estructura del triángulo del fraude: incentivo o presión, oportunidad y racionalización.

En cuanto al incentivo o presión, es lo que lleva a cometer el fraude, mientras que la oportunidad es la existencia de condiciones apropiadas para perpetrarlo y la racionalización se relaciona con las actitudes y valores éticos de la persona que le permiten de manera intencional cometer un acto deshonesto. Los auditores deben analizar estas tres dimensiones, para determinar si hay factores asociados que puedan indicar un fraude. No obstante, Michael J. Ramos (2003, p. 4) menciona que "se debe ser cauto con estas listas de factores de riesgo proporcionadas por la SAS 99, pues estas no incluyen todas las situaciones empresariales", además que hay evidencia científica que soporta que los auditores que desarrollaron su propio set de factores mediante investigación, lograron mayor efectividad en su trabajo de identificación de fraudes, que quienes se limitaron únicamente a usar la lista de factores de riesgo ilustrativa.

En consonancia con lo anterior, Glen David Moyes, Ping Lin, Raymond M. Landry y Handan Vicdan (2006) pusieron a consideración de 82 auditores internos, mediante una escala Likert, las 48 banderas rojas propuestas por la SAS 99 con el fin de establecer su efectividad para detectar fraude y su resultado arrojó que los auditores percibían 15 como más efectivas,
14 efectivas y 13 inefectivas y que las más efectivas se categorizan en los grupos de oportunidad y racionalización, siendo menos importante las relacionadas con incentivo o presión.

Otra investigación en la misma línea de la anterior se realizó en Malasia. Smith Malcolm, Normah Haji-Omar, Syed Iskandar ZulkarnainSayd-Idris e Ithnahaini Baharuddin (2005) querían identificar las banderas rojas más importantes para detectar fraudes percibidas por los auditores, para lo cual les enviaron cuestionarios por correo electrónico, con el fin de preguntar la percepción que tenían sobre los indicadores de fraude, utilizando como soporte teórico las banderas rojas de la SAS 82, Consideración del fraude en la auditoría de estados contables, empleadas en otra investigación por Barbara Apostolou, John M. Hassell, Sally A. Webber y Glenn E. Sumners (2001), las cuales, según los autores, eran similares a las propuestas por la Norma de Auditoría 240 "fraude y error" emitidas por el Instituto de Contadores de Malasia. Mediante una escala Likert, 25 banderas rojas fueron sometidas a consideración de 48 auditores en ejercicio, que encontraron significativas solo 7 variables; el predictor de riesgo de fraude valorado como el más importante fue la influencia de la administración sobre el ambiente de control o, dicho en otras palabras, un sistema de control débil y una actitud negativa de la administración.

Adicionalmente, Bryan K. Church, Jeffrey J. McMillan y Arnold Schneider (2001) investigaron los factores que afectan la percepción de los auditores internos sobre los reportes financieros fraudulentos, en relación con la utilización de procedimientos analíticos para 
su detección. Para evaluar esta percepción, a los auditores internos se les suministró información sobre una empresa que tenía ingresos operacionales con fluctuaciones inesperadas, para que dieran explicaciones sobre las causas de esto y su relación con la existencia de fraude. Para lo anterior, los auditores diligenciaron un cuestionario con afirmaciones que explicaban esta situación, las cuales debían ser puntuadas en una escala del 1 al 7 , donde 1 era totalmente de acuerdo y 7 totalmente en desacuerdo. Los auditores internos dieron explicaciones detalladas en dos situaciones paticulares: cuando los ingresos fueron mayores que los esperados y cuando se hicieron acuerdos de deuda restrictivos, además de percibir como indicio de fraude, que en la entidad haya planes de bonos basados en las ganancias de la entidad, pues estos los asocian con manipulación de los registros contables por conveniencia personal de la administración. Además, como conclusión importante, los investigadores afirman que bajo ciertas condiciones, los auditores internos son más propensos a diseñar pruebas para buscar fraude, lo cual incrementa la probabilidad de detectarlo.

Como podemos observar, desde cuando se desató la ola de escándalos corporativos, hay una preocupación creciente por determinar mecanismos, técnicas y modelos que ayuden a los auditores a detectar el fraude. No obstante, la mayoría de las investigaciones ha tendido a generar herramientas teniendo en cuenta las percepciones de los auditores externos; pocos estudios involucran auditores internos en esta labor, a sabiendas de su responsabilidad e importancia dentro de la organización. Además, no se puede desconocer que los auditores externos tienen una percepción diferente de los indicadores de fraude a los auditores internos (Moyes, 2007). En consecuencia, es necesario generar herramientas para que la auditoría interna pueda cumplir su papel fundamental de detección de fraude en la organización, y de ahí la importancia y justificación de la investigación desarrollada.

\section{Metodología del estudio}

Siguiendo los modelos de Glen David Moyes (1991); Stephen Owusu-Ansah, Glen David Moyes, Peter Babangida Oyelere y David Hay (2002); Glen David Moyes, Ping Lin, Raymond M. Landry y Handan Vicdan (2006); y Smith Malcolm, Normah Haji-Omar, Syed Iskandar Zulkarnain-Sayd-Idris e Ithnahaini Baharuddin (2005), este trabajo puso a consideración de 617 auditores internos, mediante un cuestionario de escala Likert, los indicadores de fraude establecidos por la NIA 240 con el fin de establecer su efectividad y nivel de importancia. En efecto, este trabajo de investigación está dirigido a obtener y analizar los resultados de auditores y esa delimitación está planeada para seguir con rigurosidad la teoría del diseño de modelos teóricos (Hunt, 1991) y su posterior desarrollo a otros tipos de auditores y considerando otras características cualitativas.

Si bien los auditores con más años de experiencia deberían tener diferente percepción que los auditores que están empezando sus labores en auditoría interna, no debería haber grandes diferencias al momento de proponer un modelo con las variables más importantes 
en relación con la detección de fraudes. En consecuencia, la hipótesis de esta investigación es la siguiente:

$\mathbf{P}_{1:}$ El modelo propuesto por este trabajo de investigación, considerando las variables propuestas en la NIA 240 en relación con la detección de fraudes, debiese ser estadísticamente significativo.

\subsection{Selección de la muestra}

Después de analizar el marco teórico, se procedió a seleccionar la muestra. En esta investigación, se realizó un muestreo por conveniencia no probabilístico, en el cual el entrevistador selecciona la muestra de acuerdo con el perfil que se necesita en la investigación, por lo cual la accesibilidad a los encuestados es directa y condicionada. Si bien este tipo de muestreo no tiene las ventajas de un muestreo completamente aleatorio, los objetivos de este estudio indican que no debe haber grandes diferencias en los resultados usando los dos métodos (Hair, Tatham, Anderson \& Black, 1998).

Se debe tener un adecuado cuidado científico en definir la misma condición de muestreo para el grupo bajo análisis (auditores internos). Con respecto a la muestra, la misma está constituida por 617 auditores internos con experiencia y pertenecientes a empresas reconocidas. La muestra referida a los auditores internos corresponde a auditores de Argentina, México, Perú, Bolivia y Chile. En la categoría "otros" hay auditores internos de Ecuador, Colombia, Puerto Rico y Venezuela. Esta diversidad de países de donde procede la muestra obedece a la necesidad de considerar el efec- to cultural dentro del modelo de detección de fraudes por parte de los auditores internos, como evidenció Carmen Ríos-Figueroa (2013) en su investigación.

\subsection{Definición del método de recolección de datos}

Para la recolección de los datos se diseñó un cuestionario, en el cual se optó por hacer preguntas cerradas, utilizando escalas Likert, ya que las respuestas están codificadas previamente, a diferencia de las preguntas abiertas cuyas respuestas pueden ser diversas y se hace imposible medir lo que se pretende. El método para diseñar y validar el cuestionario se describe a continuación.

\subsubsection{Definición y diseño del instrumento} William G. Zikmund, Barry J. Babin, Jon C. Carr y Mitch Griffin (2000) establecen la obligatoriedad de seguir cierta metodología al momento de desarrollar el instrumento. Siguiendo esta idea, el instrumento fue diseñado tomando el set original de 96 variables ofrecido por la NIA 240, el cual fue reconvertido en un cuestionario final con las mismas afirmaciones.

Estas afirmaciones se distribuyeron de acuerdo a las tablas 1, 2 y 3, como se observa más adelante. La tabla 1 hace mención a "factores de riesgo relativos a representaciones erróneas que se originan en la información financiera fraudulenta"; la tabla 2 hace mención a "factores de riesgo que surgen de representaciones erróneas que se originan en la malversación de activos"; la tabla 3 hace mención a "ejemplos de circunstancias que indican la posibilidad de fraude". 
Luego de la evaluación del cuestionario completo con 96 afirmaciones y dada su extensión, de acuerdo a la opinión de expertos se decidió eliminar el apéndice 3, ya que este solo entregaba ejemplos, que claramente hacían mención a la existencia de fraude y no hacían un aporte significativo para el estudio en cuestión.
$\mathrm{Al}$ nuevo cuestionario con 65 afirmaciones (Anexo 1), se le asignaron las escalas Likert, para que cada encuestado diera su opinión evaluando cada afirmación por su nivel de importancia. Los niveles de importancia van del 1 que es "totalmente en desacuerdo" al 7 "totalmente de acuerdo".

\section{Factores}

Preguntas

I. Factores de riesgo relativos a representaciones erróneas que se originan en la información financiera fraudulenta

\begin{tabular}{lcc}
\hline A. Incentivos/presiones & & \\
\hline $\begin{array}{l}\text { La estabilidad o relatividad financiera está amenazada por las condiciones económicas de la } \\
\text { industria, u operativas de la entidad, como (o según indican) las siguientes: }\end{array}$ & 01 & 07 \\
\hline $\begin{array}{l}\text { Hay una presión excesiva para que la administración cumpla los requisitos o expectativas de } \\
\text { terceros debido a lo siguiente: }\end{array}$ & 08 & 11 \\
\hline $\begin{array}{l}\text { La información disponible indica que la situación financiera personal de la administración o } \\
\text { de los encargados del gobierno corporativo está amenazada por el desempeño financiero de la } \\
\text { entidad, que se origina en lo siguiente: }\end{array}$ & 12 \\
\hline $\begin{array}{l}\text { Hay excesiva presión sobre la administración o el personal de operaciones para cumplir } \\
\text { las metas financieras establecidas por los encargados del gobierno corporativo, incluyendo } \\
\text { objetivos de incentivos de ventas o rentabilidad. }\end{array}$ & 14 \\
\hline B. Oportunidades & 15 \\
\hline $\begin{array}{l}\text { La naturaleza de la industria o de las operaciones de la entidad da oportunidades para } \\
\text { participar en información financiera fraudulenta, que puede originarse en: }\end{array}$ & 21 \\
\hline Hay un monitoreo poco efectivo de la administración como resultado de: & 22 \\
\hline Hay una estructura organizacional compleja o inestable: & 24 \\
\hline Los componentes del control interno son deficientes como resultado de: & 26 \\
\hline C. Actitudes/racionalizaciones & 29 \\
\hline
\end{tabular}

Tabla 1

Variables originales Apéndice I. NIA 240

Fuente: elaboración propia

\section{Factores}

II. Factores de riesgo que surgen de representaciones erróneas que se originan en la malversación de activos

\begin{tabular}{lcc}
\hline A. Incentivos/presiones & \\
\hline $\begin{array}{l}\text { Las obligaciones financieras personales pueden crear presión sobre la administración o los } \\
\text { empleados que tienen acceso al efectivo u otros activos susceptibles de robo, para malversar } \\
\text { estos activos }\end{array}$ & 42 \\
\hline $\begin{array}{l}\text { Las relaciones adversas entre la entidad y los empleados con acceso a efectivo u otros activos } \\
\text { susceptibles de robo pueden motivar a esos empleados a malversar los activos }\end{array}$ & 44 \\
\hline $\begin{array}{l}\text { B. Oportunidades } \\
\text { Sertas características o circunstancias pueden aumentar la susceptibilidad de los activos de }\end{array}$ & 45 \\
\hline $\begin{array}{l}\text { El control interno inadecuado sobre los activos puede aumentar la susceptibilidad de } \\
\text { malversación de estos activos. Por ejemplo, puede haber malversación de activos cuando: }\end{array}$ & 49 \\
\hline C. Actitudes/racionalizaciones & 61 \\
\hline
\end{tabular}

Tabla 2

Variables originales Apéndice II. NIA 240

Fuente: elaboración propia 
MODELO PROPUESTO PARA LA DETECCIÓN DE FRAUdES / J. SALAS-ÁVILA, N. REYES-MALdONADO / 59

\begin{tabular}{lcc}
\hline \multicolumn{1}{c}{ Factores } & Preguntas \\
\hline III. Ejemplos de circunstancias que indican la posibilidad de fraude & \\
\hline 1. Discrepancia de los registros contables & 66 & 70 \\
\hline 2. Evidencia conflictiva o faltante & 71 & 84 \\
\hline 3. Relaciones problemáticas o inusuales entre el auditor y la administración & 85 & 92 \\
\hline 4. Otros incluyen lo siguiente: & 93 & 96 \\
\hline
\end{tabular}

Tabla 3

Variables originales Apéndice III. NIA 240 Reformulada

Fuente: elaboración propia

Un asunto importante en este punto de la investigación es explicar por qué no son necesarios otros datos demográficos de los encuestados. Principalmente, las razones están relacionadas con no hacer perder mucho tiempo a los encuestados, pues los auditores internos son el segmento más complicado al contestar encuestas (Moyes, 2007). Otra razón es la parsimonia en las encuestas, ya que otros datos no son necesarios al momento de concluir.

\section{Análisis de datos y resultados}

Esta investigación está basada en la teoría que entregan las Normas Internacionales de Auditoría (NIA), las cuales son emitidas por la Federación Internacional de Contadores (IFAC). De acuerdo a esta teoría se plantearon 65 variables que mediante un cuestionario, fueron aplicadas a 617 auditores con experiencia en auditoría interna. Para analizar los datos capturados en estas 617 encuestas se aplicaron los siguientes métodos:

- Análisis factorial

- Modelo de ecuaciones estructurales, SEM

\subsection{Análisis factorial}

Se denomina genéricamente análisis factorial a una clase de métodos estadísticos multivariantes cuyo propósito principal es definir la estructura subyacente en una matriz de datos. El análisis factorial es una técnica de reducción de datos que sirve para encontrar grupos homogéneos de variables a partir de un conjunto numeroso de variables. Estos grupos homogéneos o dimensiones son formados con las variables que tienen un alto grado de nivel de correlación entre sí, siendo independientes unos de otros; estos grupos o dimensiones se llaman factores. En investigación científica relacionada con la auditoría, el análisis factorial no ha sido usado extensivamente. Primero se identifican las dimensiones separadas de la estructura y entonces se determina el grado en que se justifica cada variable por cada dimensión. Al determinar así estas dimensiones y la explicación de cada variable, se pueden lograr los objetivos principales del análisis factorial que son (García-Jiménez, Gil-Flores \& Rodríguez-Gómez, 2000):

- Descubrir las diferentes dimensiones de variabilidad común existente en cierto campo de fenómenos que se hace operativo a partir de un grupo de variables 
- Reducir datos

- Identificar la estructura mediante el resumen de datos para desarrollar modelos

Como en esta investigación se midieron 65 variables en forma simultánea (referida a dos factores, apéndices I y II), es interesante conocer de acuerdo a las respuestas de los sujetos si estas variables se relacionan entre sí, es decir, si tienen un significado en común y a qué apunta ese nuevo significado; por tanto, se hizo un análisis factorial para conocer cuáles fueron los grupos que resultaron de las encuestas realizadas y conocer a qué se refieren estos grupos de variables, es decir, a qué factor se refieren.

De acuerdo a las respuestas de los encuestados, y usando primero el apéndice I Factores de riesgo relativos a representaciones erróneas que se originan en la información financiera fraudulenta, se reagruparon las variables en 8 grupos, corre- lacionados entre sí y que apuntan a un nuevo factor que viene a constituir un nuevo modelo, que indica las variables que se debieran considerar al momento de realizar los procedimientos de auditoría para detectar un fraude. Este nuevo modelo se señala a continuación.

De los 8 factores definidos, solo 4 de ellos presenta un alfa de Cronbach adecuado, más de un 70\%, los cuales se presentan en la tabla 4. Con base en lo anterior y para seguir con rigurosidad la confiabilidad del instrumento, solo los primeros 4 factores serán analizados en la etapa final de esta investigación. Los factores finales van del 1 al 4 .

Los resultados del análisis factorial para el apéndice I están fundamentados en los siguientes factores. Los números al lado izquierdo de cada variable de las tablas 4 a la 12 muestran el número de la pregunta en el cuestionario final.

\begin{tabular}{|c|c|c|c|c|c|c|c|c|}
\hline \multicolumn{9}{|c|}{ Matriz de Componentes optimizados } \\
\hline \multicolumn{9}{|c|}{ Componentes } \\
\hline Variable & 1 & 2 & 3 & 4 & 5 & 6 & 7 & 8 \\
\hline iv37 & 0,77 & & & & & & & \\
\hline iv39 & 0.77 & & & & & & & \\
\hline iv4la & 0,72 & & & & & & & \\
\hline iv4lb & 0,60 & & & & & & & \\
\hline iv41 & 0,59 & & & & & & & \\
\hline iv41d & & 0,72 & & & & & & \\
\hline iv40 & & 0,68 & & & & & & \\
\hline iv20 & & 0,65 & & & & & & \\
\hline iv12 & & 0,49 & & & & & & \\
\hline iv41c & & 0,45 & & & & & & \\
\hline iv19 & & & 0,81 & & & & & \\
\hline iv24 & & & 0,64 & & & & & \\
\hline iv31 & & & 0,63 & & & & & \\
\hline iv25 & & & 0,48 & & & & & \\
\hline iv33 & & & 0,47 & & & & & \\
\hline iv38 & & & & 0,70 & & & & \\
\hline iv21 & & & & 0,62 & & & & \\
\hline
\end{tabular}


MODELO PROPUESTO PARA LA DETECCIÓN DE FRAUDES / J. SALAS-ÁVILA, N. REYES-MALDONADO / 595

\begin{tabular}{|c|c|c|c|c|c|c|c|c|}
\hline \multicolumn{9}{|c|}{ Matriz de Componentes optimizados } \\
\hline \multicolumn{9}{|c|}{ Componentes } \\
\hline Variable & 1 & 2 & 3 & 4 & 5 & 6 & 7 & 8 \\
\hline iv17 & & & & 0,60 & & & & \\
\hline iv23 & & & & 0,52 & & & & \\
\hline iv15 & & & & 0,45 & & & & \\
\hline iv10 & & & & & 0,72 & & & \\
\hline iv9 & & & & & 0,53 & & & \\
\hline iv11 & & & & & 0,52 & & & \\
\hline iv7 & & & & & 0,52 & & & \\
\hline iv4 & & & & & & 0,80 & & \\
\hline iv6 & & & & & & 0,60 & & \\
\hline iv18 & & & & & & 0,45 & & \\
\hline iv2 & & & & & & & 0,81 & \\
\hline iv1 & & & & & & & 0,80 & \\
\hline iv3 & & & & & & & 0,59 & \\
\hline iv28 & & & & & & & & 0,67 \\
\hline iv34 & & & & & & & & 0,62 \\
\hline iv26 & & & & & & & & 0,43 \\
\hline iv8 & & & & & 0,39 & & & \\
\hline
\end{tabular}

Tabla 4

Análisis factorial Apéndice I

Fuente: elaboración propia

37. La baja moral de la administración mayor.

39. Los pleitos entre accionistas en una entidad de control cerrado.

41a. Frecuentes pleitos con el auditor actual o precursor sobre asuntos de contabilidad, de auditoría o de información. 41b. Demandas irrazonables sobre el auditor, como restricciones poco sensatas de tiempo, respecto del término de la auditoría o de la emisión del dictamen del auditor.

41. La relación entre la administración y el auditor actual o el precursor es tirante.

Tabla 5

Factor 1. Relación laboral y profesional con la administración (Apéndice I)

Fuente: elaboración propia

Para este factor 1, Relación laboral de los administradores con auditores internos, sus 5 variables son de gran importancia, porque entregan una evidencia del actuar de los trabajadores en la organización frente a situaciones específicas, y a la revisión de las labores que realizaron en un período por un tercero externo a la empresa, como una auditoría de estados financieros. El hecho de que un empleado no mantenga una buena relación y comportamiento con el equi- po de auditoría puede entregar a la administración mayor y al equipo de auditoría pequeñas señales de alerta, pues se puede creer que el trabajo realizado no sea correcto, o que esté ocultando u omitiendo información que sea requerida para su revisión, por lo cual es necesario mantener un escepticismo profesional adecuado para poder afrontar ciertas situaciones anormales con los trabajadores de la organización. 
41d. La conducta dominante de la administración al tratar con el auditor, que especialmente implica intentos de influir en el alcance del trabajo del auditor o en la selección o continuación del personal asignado o con quién se consulta en el trabajo de auditoría.

40. Los intentos recurrentes de la administración de justificar la contabilidad marginal o inapropiada con base en su importancia relativa.

20. El uso de intermediarios de negocios, para lo cual no parece haber una clara justificación.

12. Los intereses financieros importantes en la entidad.

41c. Restricciones formales o informales sobre el auditor que, de modo inapropiado, limitan su acceso a personas o información o la capacidad de comunicarse de manera efectiva con los encargados del gobierno corporativo.

Tabla 6

Factor 2. Mal actuar de la administración (Apéndice I)

Fuente: elaboración propia

Este factor 2, Mal actuar de la administración, reúne 5 variables, que son necesarias para tener en cuenta en cualquier auditoría interna, ya que la administración mayor no puede interferir en el trabajo de una auditoría al delimitar su campo de acción y las pruebas que va a realizar, limitar o vetar al personal al que se le va a consultar sobre los procesos de la contabilidad; también se debe tener en cuenta cuando la administración mayor esté tratando de justificar operaciones de negocios poco comunes, esté realizando operaciones que no cuenten con una normativa clara y esté contabilizando de una forma incorrecta, en la que se vea sobrepasado el criterio conservador. Por ello, el auditor debe mantener un escepticismo profesional alto durante su proceso de auditoría.

Este factor 3, Malas prácticas de la administración, presenta 5 variables relevantes para un examen de auditoría, ya que se debe tener un conocimiento acabado de la organización en cuanto a negocios en el extranjero, cuál es la normativa que la rige o simplemente cómo se lleva la contabilidad, ya que la administración mayor puede aplicar criterios contables que no sean los más conservadores para la organización al realizar sus estados financieros, sobre todo en lo que tienen qué ver con las estimaciones, o tratando de hacer ver más atractivas las empresas que transan en la bolsa para los inversionistas, mediante la intervención en los resultados para inflar las utilidades y así poder adquirir mayor inversión de terceros con el fin de aumentar la cantidad de capital para los negocios futuros. Estructuras administrativas pesadas y exentas de control forman parte de este factor.

19. Las operaciones importantes localizadas o conducidas en el extranjero en jurisdicciones donde hay entornos y culturas de negocios diferentes.

24. La dificultad para determinar la organización o las personas que tienen interés de control en la entidad.

31. La excesiva participación no financiera de la administración en - o preocupación por-la selección de políticas contables o la determinación de estimaciones importantes.

25. Una estructura organizacional exageradamente compleja, que implica entidades legales inusuales o líneas gerenciales de autoridad.

33. El interés excesivo de la administración en mantener o aumentar el precio de las acciones de la entidad o la tendencia de las utilidades.

\section{Tabla 7}

Factor 3. Malas prácticas de la administración (Apéndice I)

Fuente: elaboración propia 
38. El dueño-gerente no hace distinción entre transacciones personales y de negocios.

21. Una importante cuenta bancaria u operaciones de subsidiarias o sucursales en jurisdicciones de paraísos fiscales para las que no parece haber una clara justificación de negocios.

17. Los activos, pasivos, ingresos o gastos basados en estimaciones importantes, a las que se aplican juicios subjetivos o a las que les falta seguridad y son difíciles de corroborar.

23. La vigilancia poco efectiva por los encargados del gobierno corporativo sobre el proceso de información financiera y control interno.

15. Las transacciones importantes de partes relacionadas que no sean del curso ordinario de los negocios, con entidades relacionadas no auditadas o auditadas por otra firma.

Tabla 8

Factor 4. Mala administración de recursos financieros (Apéndice I)

Fuente: elaboración propia

Este factor 4, Mala administración de recursos financieros, reúne 5 variables de gran utilidad para la auditoría y la gestión de las empresas, ya que al saber que los dueños no hacen una distinción clara entre sus transacciones personales y las de su empresa, se infiere que los estados financieros están mal expresados, por lo que hay que lograr identificar aquellas transacciones personales, pues estas son malas prácticas financieras de la administración donde se transgrede el principio de entidad contable. También hay que tener un especial cuidado en aquellas cuentas que se refieren a estimaciones otorgadas por la administración, que por la utilización de su criterio demanda un mayor cuidado en la auditoría, por lo que la empresa debe tener un respaldo o una justificación clara de los factores o montos a utilizar para una estimación contable. Adicionalmente, entre estas variables se deben considerar las transacciones que estén fuera del giro de la empresa realizadas con terceros que no tengan una organización legalmente constituida, o con las empresas relacionadas, ya que pueden estar traspasándose las utilidades o pérdidas entre ellas, como una empresa que esté vendiendo productos a otra por un valor por debajo de su costo.

Siguiendo con las respuestas de los auditores internos y efectuando el mismo análisis estadístico de confiabilidad del instrumento realizado para el apéndice I, en el caso del apéndice II Factores de riesgo que surgen de representaciones erróneas que se originan en la malversación de activos, de los 4 factores definidos en el análisis (tabla 9) solo 3 de ellos presentaron un alfa de Cronbach adecuado, más de $70 \%$.

Con base en lo anterior y para seguir con rigurosidad la confiabilidad del instrumento, solo los primeros 3 factores serán analizados en la etapa final de esta investigación. Los factores finales van del 1 al 3 de acuerdo a la tabla 9, pero de ahora en adelante son los factores $5 \mathrm{al}$ 7, para tener en cuenta los factores ya definidos en el apéndice I (factor $1 \mathrm{al} 4$ ). 


\begin{tabular}{|c|c|c|c|c|}
\hline \multicolumn{5}{|c|}{ Matriz de Componentes optimizados } \\
\hline \multirow{2}{*}{ Variable } & \multicolumn{4}{|c|}{$\begin{array}{l}\text { Componentes } \\
\end{array}$} \\
\hline & 1 & 2 & 3 & 4 \\
\hline iiv19 & 0,75 & & & \\
\hline iiv24 & 0,70 & & & \\
\hline iiv14 & 0,68 & & & \\
\hline iiv18 & 0,64 & & & \\
\hline iiv10 & 0,43 & & & \\
\hline iiv6 & & 0,84 & & \\
\hline iiv7 & & 0,73 & & \\
\hline iiv5 & & 0,71 & & \\
\hline iiv4 & & 0,62 & & \\
\hline iiv21 & & & 0,79 & \\
\hline iiv20 & & & 0,68 & \\
\hline iiv15 & & & 0,67 & \\
\hline iiv16 & & & 0,67 & \\
\hline iiv17 & & & 0,54 & \\
\hline iiv23 & & & 0,38 & \\
\hline iiv9 & & & & 0,67 \\
\hline iiv11 & & & & 0,66 \\
\hline iiv12 & & & & 0,66 \\
\hline
\end{tabular}

Tabla 9

Análisis factorial Apéndice II

Fuente: elaboración propia

Los resultados del análisis factorial para el apéndice II se fundamentan en los siguientes factores:

19. Los controles de accesos inadecuados sobre los registros automatizados, incluyendo controles sobre revisión de sistemas de registros de eventos por computadora.

24. La tolerancia de pequeños robos.

14. Salvaguardas físicas inadecuadas sobre efectivos, inversiones, inventario o activos fijos.

18. La administración tiene un entendimiento inadecuado de la tecnología de la información, lo que facilita a los empleados de este departamento a perpetrar una malversación.

10. La vigilancia inadecuada de la administración de los empleados encargados del manejo de activos, por ejemplo, supervisión o monitoreo inadecuados de localidades lejanas.

Tabla 10

Factor 5. Salvaguardas físicas (Apéndice II)

Fuente: elaboración propia

El factor 5, Salvaguardas físicas, agrupa 5 variables relacionadas con la protección de los activos, lo cual es una actividad constante y fundamental en las organizaciones, ya que cada día se les está dando mayor importancia a estos procedimientos de control, para resguardar la seguridad tanto de los activos existentes en la organización, como de la información contenida en los sistemas computacionales. Por ello, los controles de accesos y delimitación de funcio- 
nes son importantes al momento de entregar un cargo de confianza a los trabajadores de la organización, ya que se debe saber quiénes son las personas que supervisan y autorizan ciertas transacciones, de tal forma que se tenga claro quiénes son los involucrados en determinados procesos. Por ello, las empresas cada vez demandan más los servicios de auditores, para que revisen y sugieran mejoras a su control interno, y poder ofrecer informes financieros bien expresados y valorados, lo que hace indispensable que la administración mayor tenga un conocimiento claro de los sistemas computacionales, de las inversiones, las existencias y los negocios nuevos que la empresa mantenga o emprenda a lo largo de su vida económica.

6. Los activos fácilmente convertibles, bonos al portador, diamantes o chips de computadora.

7. Activos fijos de tamaño pequeño, fácilmente comercializables o que carecen de una identificación observable de propiedad.

5. Los artículos de inventario de tamaño pequeño, de alto valor o de gran demanda.

4. Cuando hay a la mano, o se procesa, gran cantidad de efectivo.

Tabla 11

Factor 6. Vulnerabilidad de activos (Apéndice II)

Fuente: elaboración propia

Este factor 6, Vulnerabilidad de activos, reúne 4 variables a las cuales la empresa les entrega mayor atención en su plan de riesgos de fraude y a los que durante la auditoría se les pone mayor énfasis en su revisión, ya que estos son los bienes con mayor vulnerabilidad de ser extraídos de la empresa por su facilidad de portar y alto valor comercial. Los productos de este tipo son los más atractivos para un trabajador que piense realizar un fraude a la empresa; por ello, la ad- ministración mayor debería mantener más cantidad de controles para los activos más líquidos y fácilmente convertibles, como los activos fijos pequeños de alto valor. Por ello, se deben realizar en forma periódica inventarios y arqueos al efectivo manejado en la organización, a los bonos y títulos contraídos por la empresa; además, se debería tener bajo llave los activos de mayor valor y separados de otros activos a cargo de una persona de plena confianza de la administración.

21. La indiferencia al control interno sobre malversación de activos, al sobrepasar los controles existentes o al dejar de corregir las conocidas deficiencias de control interno.

20. El comportamiento que indica descontento o insatisfacción con la entidad o con su trato al empleado.

15. La falta de conciliaciones de activos, completas y oportunas.

16. La falta de documentación de transacciones oportunas y apropiadas, por ejemplo, crédito por devoluciones de mercancía.

17. La falta de vacaciones obligatorias para empleados que desempeñan funciones de control clave.

23. Los cambios en el comportamiento o estilo de vida.

Tabla 12

Factor 7. Ambiente de control (Apéndice II)

Fuente: elaboración propia 
El factor 7, Ambiente de control, reúne variables importantes para la organización y para los auditores internos, ya que muestran ciertas situaciones que no deberían ocurrir en el curso ordinario de las labores de la alta administración o de sus trabajadores en terreno, pues afectan la conciencia de control de la organización. Por ello, una monitorización constante a su control interno es la única forma de ir corrigiendo el incumplimiento a los controles existentes, pues se debe llevar un control de las existencias, las mermas y los faltantes en bodega para ajustar las cantidades y con ello asegurar que estén bien valoradas en los informes de gestión y en los estados financieros. También se deben realizar rotaciones de labores para que ningún empleado sea indispensable en ciertos niveles de la organización, para que cuando tome sus vacaciones legales no falte el trabajador que tiene el conocimiento exclusivo de cómo operan ciertos procesos en la empresa, pues una auditoría considera con mayor riesgo aquel proceso realizado por una sola persona, que no cuente con un supervisor ni autorización en sus labores y se considere indispensable para esta labor.

Otro punto muy importante en este factor es el relacionado con el trato a los trabajadores, ya que un empleado descontento no se sentirá identificado con la cultura de control de la entidad y, por ende, puede no cumplir los controles establecidos o incluso generar incentivos éticos para sobrepasarlos y cometer fraude, todo por falta de sentido de pertenencia con la organización.

\subsection{Modelo de ecuaciones estructurales} (SEM)

No es un objetivo primordial entregar una explicación extensa sobre los modelos de ecuacio- nes estructurales, por lo cual solo se describirán los objetivos específicos de esta herramienta estadística y cómo se relaciona con los objetivos de este trabajo de investigación.

Tanto el análisis de varianza como el análisis factorial tienen una limitante en común: la capacidad de cada técnica de examinar solo una relación a la vez. Por tal razón, se decidió utilizar un modelo de ecuaciones estructurales, el cual abarca una familia de modelos conocidos con muchos nombres, entre ellos, análisis de la estructura de la covarianza, análisis de variable latente y análisis de factor confirmatorio, cuyo valor radica en que esta técnica se ha convertido en una herramienta integral. Todas las técnicas SEM se distinguen por dos características fundamentales (Batista-Foguet \& Coenders-Gallart, 2000):

- Estimación de relaciones de dependencia múltiples y cruzadas

- La capacidad de representar conceptos no observados en estas relaciones y tener en cuenta el error de medida en el proceso de estimación

Después de examinar los resultados entregados por el análisis exploratorio, se realizó un análisis confirmatorio con la herramienta estadística AMOS 8.0. El objetivo de usar esta herramienta fue cumplir el fin propuesto al inicio de esta investigación, y que consistía en proponer un modelo para la detección de fraudes, con las variables que mejor demuestren la experiencia y el conocimiento de los auditores externos en relación con las variables ofrecidas por la NIA 240.

En efecto, el modelo propuesto por este trabajo de investigación consiste en realizar un análisis confirmatorio de la NIA 240. El modelo propuesto es el siguiente: 
MOdELO PROPUESTO PARA LA DETECCIÓN DE FRAUdes / J. SALAS-ÁVILA, N. REYES-MALdONAdo / 601

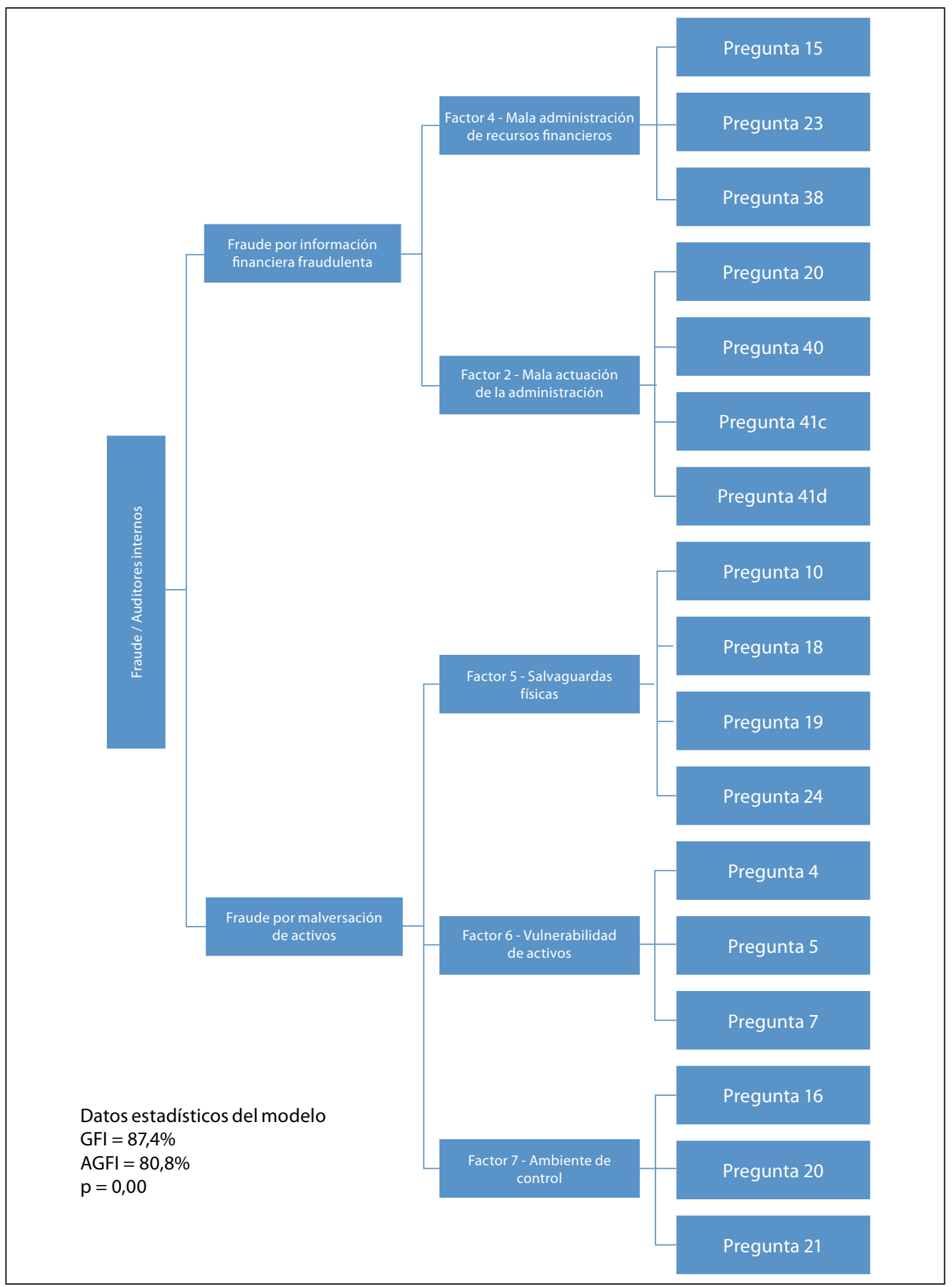

Figura 1

Modelo confirmatorio para la detección de fraudes 
El modelo propuesto contiene 17 variables en total. Respecto a las variables relacionadas con el apéndice I, Factores de riesgo relativos a representaciones erróneas que se originan en la información financiera fraudulenta, define que con el uso de 7 variables, encontramos, con más de un $80 \%$ de precisión, la posibilidad de fraudes en una revisión de auditoría interna relativa a la información financiera fraudulenta, como se presenta a continuación:

15. Las transacciones importantes de partes relacionadas que no sean del curso ordinario de los negocios, con entidades relacionadas no auditadas o auditadas por otra firma.

23. La vigilancia poco efectiva por los encargados del gobierno corporativo sobre el proceso de información financiera y control interno.

38. El dueño-gerente no hace distinción entre transacciones personales y de negocios.

Tabla 13

Factor 4. Mala administración de recursos financieros (Apéndice I)

Fuente: elaboración propia

20. El uso de intermediarios de negocios, para lo cual no parece haber una clara justificación de negocios.

40. Los intentos recurrentes de la administración de justificar contabilidad marginal o inapropiada con base en su importancia relativa.

41c. Restricciones formales o informales sobre el auditor que, de modo inapropiado, limitan su acceso a personas o información o la capacidad de comunicarse de manera efectiva con los encargados del gobierno corporativo.

41d. La conducta dominante de la administración al tratar con el auditor, que especialmente implica intentos de influir en el alcance del trabajo del auditor o en la selección o continuación del personal asignado o con quién se consulta en el trabajo de auditoría.

\section{Tabla 14}

Factor 2. Mal actuar de la administración (Apéndice I)

Fuente: elaboración propia

El modelo también considera variables relacionadas con el apéndice II, Factores de riesgo que surgen de representaciones erróneas que se originan en la malversación de activos, define que con el uso de 10 variables, encontramos, con más de un $80 \%$ de precisión, la posibilidad de fraudes en una revisión de auditoría interna relativas a la malversación de activos, variables que se presentan a continuación:

10. La vigilancia inadecuada de la administración de los empleados encargados del manejo de activos, por ejemplo, supervisión o monitoreo inadecuados de localidades lejanas.

18. La administración tiene un entendimiento inadecuado de la tecnología de la información, lo que facilita a los empleados de este departamento perpetrar una malversación.

19. Los controles de accesos inadecuados sobre los registros automatizados, incluyendo controles sobre revisión de sistemas de registros de eventos por computadora.

24. La tolerancia de pequeños robos.

Tabla 15

Factor 5. Salvaguardas físicas (Apéndice II)

Fuente: elaboración propia 
4. Cuando hay a la mano, o se procesa, gran cantidad de efectivo.

5. Los artículos de inventario que son de tamaño pequeño, de alto valor, o de gran demanda.

7. Activos fijos de tamaño pequeño, fácilmente comercializables o que carecen de una identificación observable de propiedad.

Tabla 16

Factor 6. Vulnerabilidad de activos (Apéndice II)

Fuente: elaboración propia

16. La falta de documentación de transacciones oportunas y apropiadas, por ejemplo, crédito por devoluciones de mercancía.

20. El comportamiento que indica descontento o insatisfacción con la entidad o con su trato al empleado.

21. La indiferencia al control interno sobre malversación de activos, al sobrepasar los controles existentes o al dejar de corregir las conocidas deficiencias de control interno.

Tabla 17

Factor 7. Ambiente de control (Apéndice II)

Fuente: elaboración propia

\section{Conclusiones}

Los fraudes corporativos ocurridos en las organizaciones en el mercado mundial, trajeron muchos cuestionamientos sobre las responsabilidades del trabajo de auditoría y su relación con la prevención y detección del fraude. En efecto, los gobiernos, las empresas y los organismos profesionales están preocupados por la incidencia constante de fraudes y sobre todo por la no detección temprana de los mismos, lo cual evitaría incontables pérdidas económicas, financieras y sociales para todas las partes.

Los auditores - ya sean externos o internos- se han convertido en un mecanismo de apoyo para las empresas en cuanto al manejo de esta situación, pero no se puede caer en el error de poner toda la responsabilidad del fraude en los auditores. La organización no puede desconocer su papel fundamental en el manejo del riesgo de fraude y para esta función hay lineamientos como los establecidos en la Guía prác- tica para la administración del riesgo de fraude en los negocios, emitida conjuntamente por el Instituto de Auditores Internos, IIA; el Instituto Americano de Contadores Públicos Certificados, AICPA y la Asociación de Examinadores de Fraude Certificados, ACFE, en la que queda claro que son las empresas las responsables de gestionar el fraude mediante sus sistemas de gobierno corporativo, junto con la identificación de riesgos de fraude y el establecimiento de controles de prevención, detección y respuesta al mismo (ACFE, IIA \& AICPA, 2008).

El rol del auditor frente al fraude consiste en su detección, en un ambiente de control establecido. Si analizamos los hallazgos de la investigación desde este punto de vista, 617 auditores internos con experiencia evaluaron 65 indicadores de fraude relacionados en la NIA 240 y según sus percepciones, 17 variables son las más significativas para evaluar la presencia de un fraude en la organización. De estas 17 variables, 7 tienen qué ver con fraudes 
relacionados con información financiera fraudulenta y 10 con malversación de activos.

Respecto a la información financiera fraudulenta, queda claro que la administración tiene un peso importante en esta situación, pues las variables resultantes tienen qué ver con mala administración de recursos y mala actuación de la administración. En cuanto a la mala administración de recursos, la falta de vigilancia del control interno y del proceso de generación de información financiera, sumada a no diferenciar transacciones del negocio de asuntos personales, o a realizar transacciones con partes relacionadas que no son del curso ordinario de los negocios, evidencia el desorden y las malas prácticas administrativas. $\mathrm{Si}$ a lo anterior le sumamos actitudes negativas de la administración, como el intento de justificar contabilidad o transacciones inadecuadas, además de restringir el alcance y el trabajo del auditor, dan para pensar que algo extraño está ocurriendo en la organización.

En cuanto a la malversación de activos, la falta de salvaguardas físicas y la vulnerabilidad de activos son consecuencias de un ambiente de control débil o inexistente, lo que da oportunidades a los defraudadores de cometer sus ilícitos. No se puede desconocer que para perpetrar un fraude se debe tener la capacidad de percibir la oportunidad de ejecutarlo y un defraudador usualmente es una persona que entiende el sistema de control interno y por ende percibe sus debilidades, además de tener una motivación personal de cometer un fraude y sentir que el riesgo de ser descubierto es mínimo (Wolfe \& Hermanson, 2004).
En efecto, cuando no hay controles para las tecnologías de información, cuando no hay una adecuada supervisión de los empleados que manejan activos, cuando se toleran robos o cuando los activos vulnerables como efectivo, inventario o activos fijos carecen de controles o no se supervisan, la oportunidad para cometer fraude aumenta. Además, si la administración conoce todas estas fallas y su actitud es de indiferencia, o la administración es la que permite que se sobrepasen los controles existentes, no controla y no se preocupa de ello y además tolera la falta de controles, como la documentación soporte, las autorizaciones y por si fuera poco, no se preocupa por el ambiente laboral y la insatisfacción creciente de los empleados, la posibilidad de que un fraude se esté perpetrando en esa organización es muy alta, pues las oportunidades están dadas gracias a que no hay un ambiente adecuado de control.

Finalmente, los auditores internos son los más cercanos a estas realidades, los que viven el día a día en las empresas, y su responsabilidad es evaluar la efectividad de la gestión y de la administración de los riesgos del negocio, incluido el riesgo de fraude, junto con la efectividad de los controles establecidos para prevenirlo, detectarlo y darle respuesta, por lo cual los auditores internos constituyen un mecanismo de disuasión y detección, mas no de prevención, pues en últimas, la que realmente previene un fraude es la organización al establecer controles específicos y supervisar su correcto funcionamiento. Además, si los altos mandos administrativos no desarrollan esta conciencia de control, el auditor ya sea interno o externo solo puede sentarse a esperar que el 
próximo fraude se presente y detectarlo cuando ya esté ocurriendo y algunos de los 17 indicadores arriba mencionados den cuenta de la situación, con la diferencia de que se podrá detectar más pronto, lo cual minimiza las consecuencias, pero con la convicción de que el fraude pudo haberse evitado si se hubiera administrado mejor el ambiente de control y el riesgo de su ocurrencia.

\section{Referencias}

Alleyne, Philmore \& Howard, Michael (2005). An Exploratory Study of Auditors' Responsibility for Fraud Detection in Barbados. Managerial Auditing Journal, 20 (3), 284-303. Disponible en: https://www. academia.edu/3255480/An_exploratory_ study_of_auditors_responsibility_for_ fraud_detection_in_Barbados American Institute of Certified Public Accountants, AICPA (2002). SAS 99, Consideration of Fraud in a Financial Statement Audit. Disponible en: https:// www.aicpa.org/Research/Standards/ AuditAttest/DownloadableDocuments/AU00316.pdf

Apostolou, Barbara; Hassell, John M.; Webber, Sally A. \& Sumners, Glenn E. (2001). The Relative Importance of Management Fraud Risk Factors. Behavioral Research in Accounting, 13, 1-24.

Asare, Stephen K. \& Wright, Arnold M. (2004). The Effectiveness of Alternative Risk Assessment and Program Planning Tools in a Fraud Setting. Contemporary Accounting Research, 21 (2), 325-352.
Association of Certified Fraud Examiners, ACFE (2010). Report to the Nations on Occupational Fraud and Abuse. Austin, Texas: Association of Certified Fraud Examiners. Disponible en: http://www.acfe. com/rttn-international.aspx

Association of Certified Fraud Examiners, ACFE (2014). Report to the Nations on Occupational Fraud and Abuse. 2014 Global Fraud Study. Austin, Texas: Association of Certified Fraud Examiners. Disponible en Association of Certified Fraud Examiners: http://www.acfe.com/rttn/docs/2014report-to-nations.pdf

Badillo-Ayala, Jorge (2008). Auditoría forense: más que una especialidad profesional una misión: prevenir y detectar el fraude financiero. Disponible en: https://na.theiia.org/ translations/PublicDocuments/ auditoría Forense_Una_Misi\%C3\%B3n_JBadillo_ Mayo08(14023).pdf

Batista-Foguet, Joan Manuel \& Coenders-Gallart, Germà (2000). Modelo de ecuaciones estructurales: modelos para el análisis de relaciones causales. Madrid: La Muralla S.A.

Church, Bryan K.; McMillan, Jeffrey J. \& Schneider, Arnold (2001). Factors Affecting Internal Auditors' Consideration of Fraudulent Financial Reporting during Analytical Procedures. Auditing: A Journal of Practice \& Theory, 20 (1), 65-80.

Coram, Paul; Ferguson, Colin \& Moroney, Robyn (2008). Internal Audit, Alternative Internal Audit Structures and the Level of Misappropriation of Assets Fraud. Accounting and Finance, 48 (4), 543-559. 
DeZoort, Todd \& Harrison, Paul (2008). An Evaluation of Internal Auditor Responsibility for Fraud Detection. Florida: The Institute of Internal Auditor.

Estados Unidos (2002). Ley Sarbanes-Oxley. Disponible en: http://www.soxlaw.com/

Farber, David B. (2005). Restoring Trust After Fraud: Does Corporate Governance Matter? The Accounting Review, 80 (2), 539-561.

García-Benau, María Antonia \& Humphrey, Christopher (1995). La auditoría y el fraude: algunas consideraciones internacionales. Revista Española de Financiación y Contabilidad, REFC, 24 (84), 697-726. Disponible en: https://www.researchgate.net/ publication/28216537_La_auditoria_y_el_ fraude_Algunas_consideraciones_internacionales

García-Jiménez, Eduardo; Gil-Flores, Javier \& Rodríguez-Gómez, Gregorio (2000). Análisis factorial. Colección Cuadernos de Estadística. Madrid: La Muralla S.A.

Gonzalvo, Enrique (2003). Una guía para prevenir el fraude. Buenos Aires: Instituto de Auditores Internos de Argentina, IAIA. Disponible en: http://www.iaia.org.ar/revistas/ normaria/Normaria06.pdf

Gurovich, Leopoldo Isaac (2006). Informe $N^{\circ} 14$. Área auditoría: consideraciones del fraude y del error en una auditoría de estados contables. Rosario: Federación Argentina de Consejos Profesionales de Ciencias Económicas (FACPCE) \& Centro de Estudios Científicos y Técnicos (CECyT). Disponible en: http://www.facpce.org. ar:8080/miniportal/archivos/informes_del_ cecyt/area_auditoria_informe_14.pdf
Hair, Joseph F.; Tatham, Ronald L.; Anderson, Rolph E. \& Black, William C. (1998). Multivariate Data Analysis. Volume 5. Harlow, Essex: Prentice Hall.

Hunt, Shelby D. (1991). Modern Marketing Theory: Critical Issues in the Philosophy of Marketing Science. Cincinnati, Ohio: SouthWestern Publishing Co.

Institute of Internal Auditors, IIA (2013). Normas internacionales para el ejercicio profesional de la auditoría interna.

Disponible en: https://na.theiia.org/ translations/PublicDocuments/IPPF\%20 Standards\%20Markup\%20Changes\%20 2013-01\%20vs\%202011-01\%20Spanish.pdf

Institute of Internal Auditors, IIA; American Institute of Certified Public Accountants, AICPA \& Association of Certified Fraud Examiners, ACFE (2008). Managing the Business Risk of Fraud: A Practical Guide. Disponible en: https://www.acfe.com/ uploadedFiles/ACFE_Website/Content/ documents/managing-business-risk.pdf International Auditing and Assurance Standards Board, IAASB (2009). International Standard on Auditing (ISAs) 240: The Auditor's Responsibility to Consider Fraud and Error in an Audit of Financial Statements. International Auditing and Assurance Standards Board, IAASB \& International Federation of Accounting Committee, IFAC.

Kaplan, Steven E.; Richmond-Pope, Kelly \& Samuels, Janet A. (2011). An Examination of the Effect of Inquiry and Auditor Type on Reporting Intentions for Fraud. Auditing: A Journal of Practice \& Theory, 30 (4), 29-49. 
Malcolm, Smith; Haji-Omar, Normah; Zulkarnain-Sayd-Idris, Syed Iskandar \& Baharuddin, Ithnahaini (2005). Auditors' Perception of Fraud Risk Indicators: Malaysian Evidence. Managerial Auditing Journal, 20 (1), 73-85.

Moyes, Glen David (1991). An Analysis of the Effectiveness of Specific Auditing Techniques for Detecting Fraud as Perceived by Three Different Auditor Groups. Doctor of Business Administration Thesis. San Diego: United States International University.

Moyes, Glen David (2007). The Differences In Perceived Level of Fraud-Detecting Effectiveness of SAS No. 99 Red Flags between External and Internal Auditors. Journal of Business \& Economics Research, JBER, 5 (6), 9-26. Disponible en: http:// www.cluteinstitute.com/ojs/index.php/ JBER/article/view/2551/2597

Moyes, Glen David; Lin, Ping; Landry, Raymond M. \& Vicdan, Handan (2006). Internal Auditor's Perceptions of the Effectiveness of Red Flags to Detect Fraudulent Financial Reporting. Journal of Accounting, Ethics \& Public Policy, 6 (1), 1-28. Disponible en: http://papers.ssrn.com/sol3/ papers.cfm?abstract_id $=961457$

Owusu-Ansah, Stephen; Moyes, Glen David; Oyelere, Peter Babangida \& Hay, David (2002). An Empirical Analysis of the Likelihood of Detecting Fraud in New Zealand. Managerial Auditing Journal, 17 (4), 192-204. Ramos, Michael J. (2003). Auditor's Responsibility for Fraud Detection: SAS No. 99 Introduces a New Era in Auditors' Requirements. Journal of Accountancy,
195 (1), 1-9. Disponible en: http://www. journalofaccountancy.com/issues/2003/jan/ auditorsresponsibilityforfrauddetection.html Ríos-Figueroa, Carmen (2013). Efecto del conocimiento cultural en la percepción de los auditores: controles internos y fraude. Revista Internacional Administración \& Finanzas, 6 (2), 15-32. Disponible en: http:// papers.ssrn.com/sol3/papers.cfm?abstract_ id $=2156409$

Soberanis-Aguirre de Rueda, María de los Ángeles \& Herrera-Soria, Francisco Ernesto (2013). La auditoría interna en la prevención y detección de fraudes. XXX Conferencia Interamericana de Contabilidad, Punta del Este, Uruguay, Colegio de Contadores, Economistas y Administradores del Uruguay, CCEAU. Disponible en: http:// www.cpcecba.org.ar/media/img/paginas/ La\%20Auditor\%C3\%ADa\%20Interna\%20 En\%20La\%20Detecci\%C3\%B3n\%20Y\%20 Prevenci\%C3\%B3n\%20De\%20Fraudes.pdf Tak, Isa; Morariu, Ana \& Guney, Ayhan (2012). The Importance of the Financial Audit Perception in the Internal Control Structure to Prevent the Financial Crises: Evidence from Romania. Journal of WEI Business and Economics, 1 (1), 10-18. Disponible en: http://westeastinstitute. com/journals/wp-content/uploads/2013/02/ ZG12-134-Isa-tak-Morariu-Ana-and-AyhanGuney-Full-Paper-Ready.pdf Villacorta-Hernández, Miguel Ángel (2014). Responsabilidad del auditor ante el fraude empresarial. Global Conference on Business and Finance Proceedings, The Institute for Business \& Finance Research, IBFR, 9 (2), 
1828-1833. Disponible en: http://www. theibfr.com/ARCHIVE/ISSN-1941-9589V9-N2-2014.pdf, http://www.theibfr.com/ proceedings.htm

Whittington, O. Ray \& Pany, Kurt (2005). Principios de auditoría. México: McGraw-Hill, Interamericana de México.

Wolfe, David T. \& Hermanson, Dana R. (2004). The Fraud Diamond: Considering the Four Elements of Fraud. The CPA Journal, 38-42. Disponible en: http://wweb.uta.edu/faculty/ subraman/EMBA-FTW2009/Articles/ Fraud\%20Diamond\%20Four\%20Elements. CPAJ2004.pdf

Zikmund, William G.; Babin, Barry J.; Carr, Jon C. \& Griffin, Mitch (2000). Business Research Methods. Volume 6. San Diego, Cali- fornia: The Dryden Press, Harcourt Brace College Publishers.

- Fecha de recepción: 24 de agosto de 2015

- Fecha de aceptación: 26 de Abril de 2016

- Disponible en línea: 15 de mayo de 2016

\section{Para citar este artículo}

Salas-Ávila, J. A. \& Reyes-Maldonado, N. M. (2015). Modelo propuesto para la detección de fraudes por parte de los auditores internos basado en las normas internacionales de auditoría. Cuadernos de Contabilidad, 16(42), 579-623. http://dx.doi. org/10.11144/Javeriana.cc16-42.mpdf 
MOdELO PROPUESTO PARA LA DETECCIÓN DE FRAUdes / J. SALAS-ÁVILA, N. REYES-MALDONADo / 609

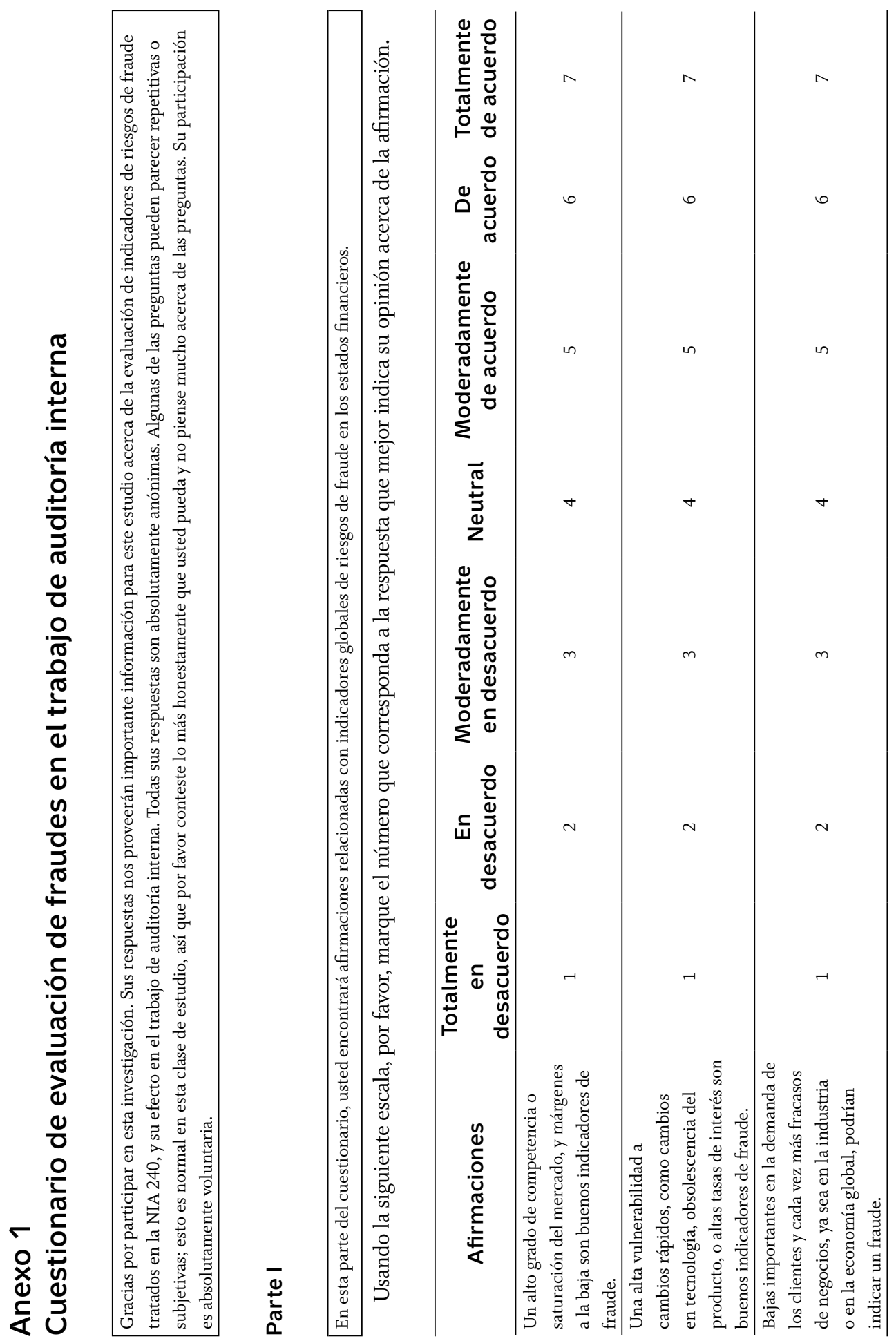


610 / VOL. 16/ NO. 42 / SEPTIEMBRE-DICIEMBRE 2015

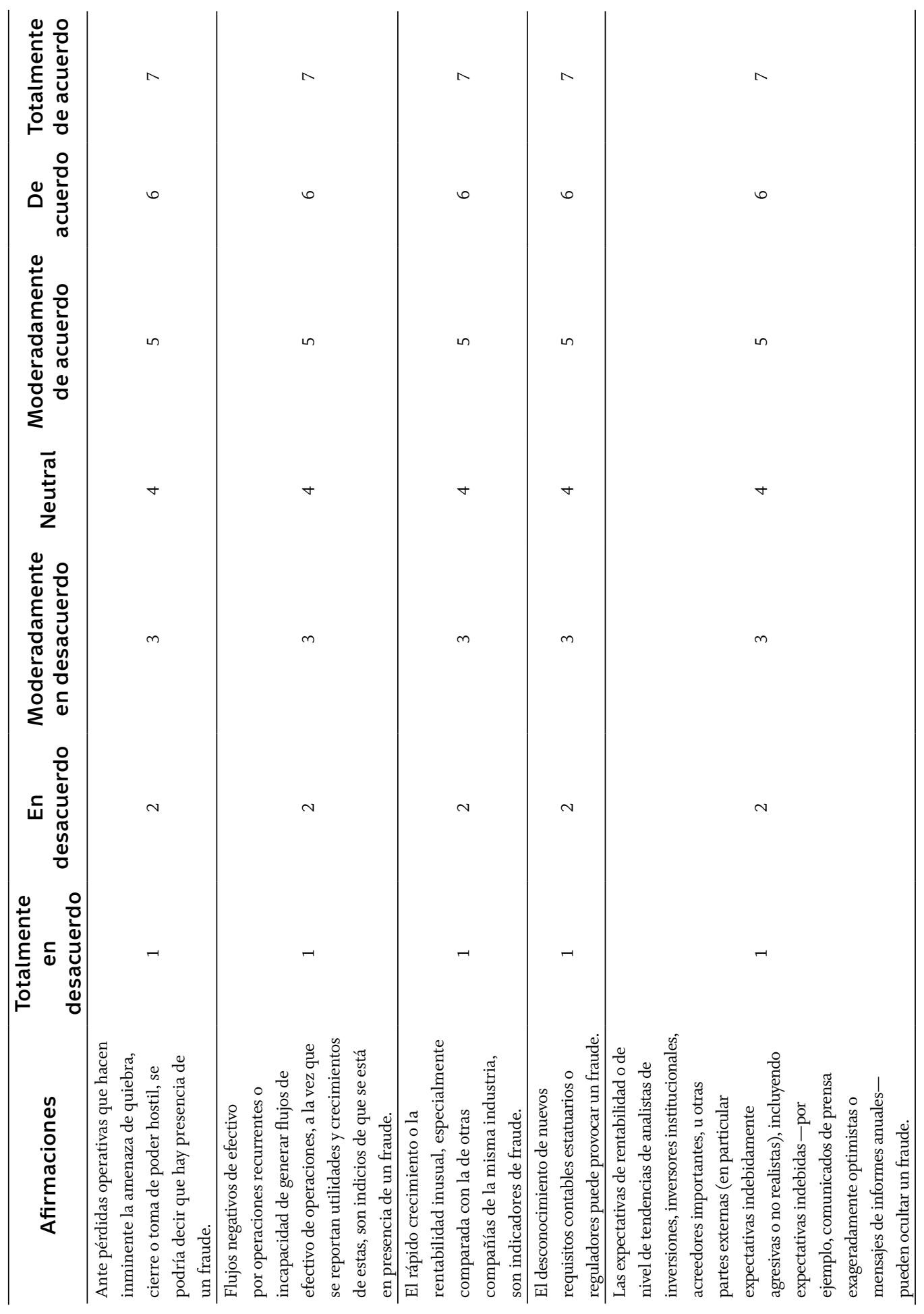


MODELO PROPUESTO PARA LA DETECCIÓN DE FRAUdes / J. SALAS-ÁviLA, N. REYES-MALDONAdo / 611

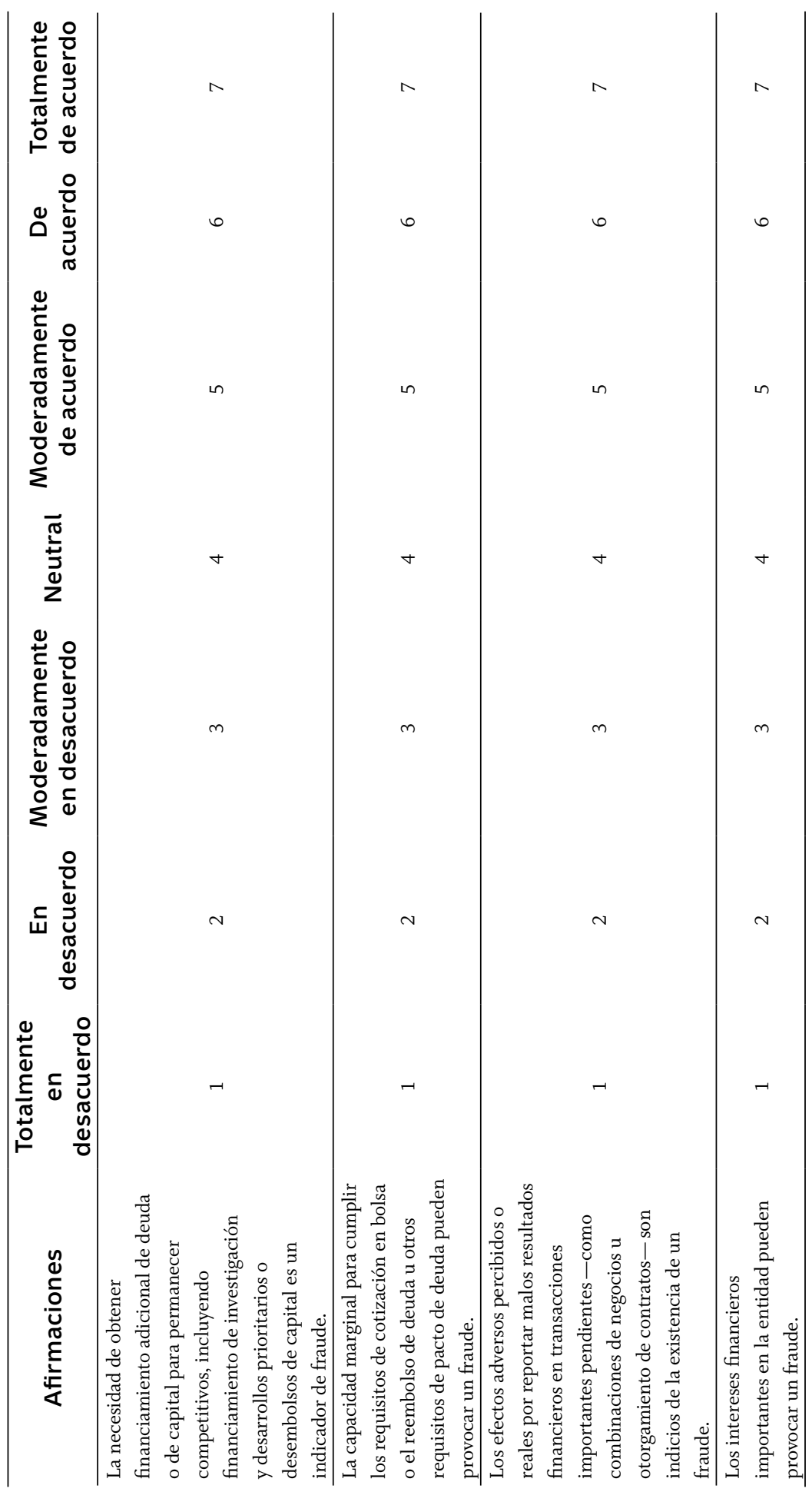


612 / VOL. 16/ NO. 42 / SEPTIEMBRE-DICIEMBRE 2015

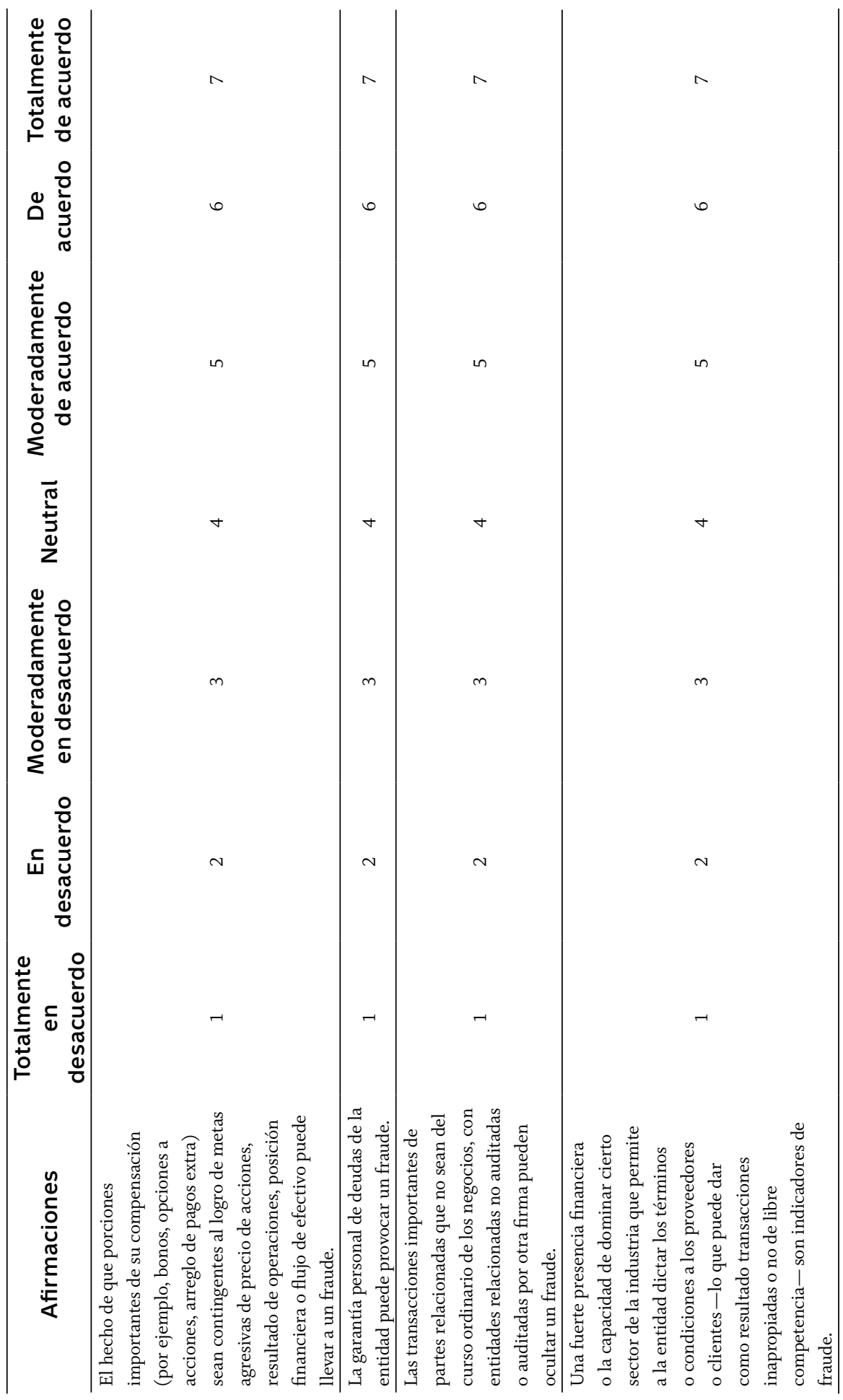


MODELO PROPUESTO PARA LA DETECCIÓN DE FRAUDES / J. SALAS-ÁVILA, N. REYES-MALDONADO / 613

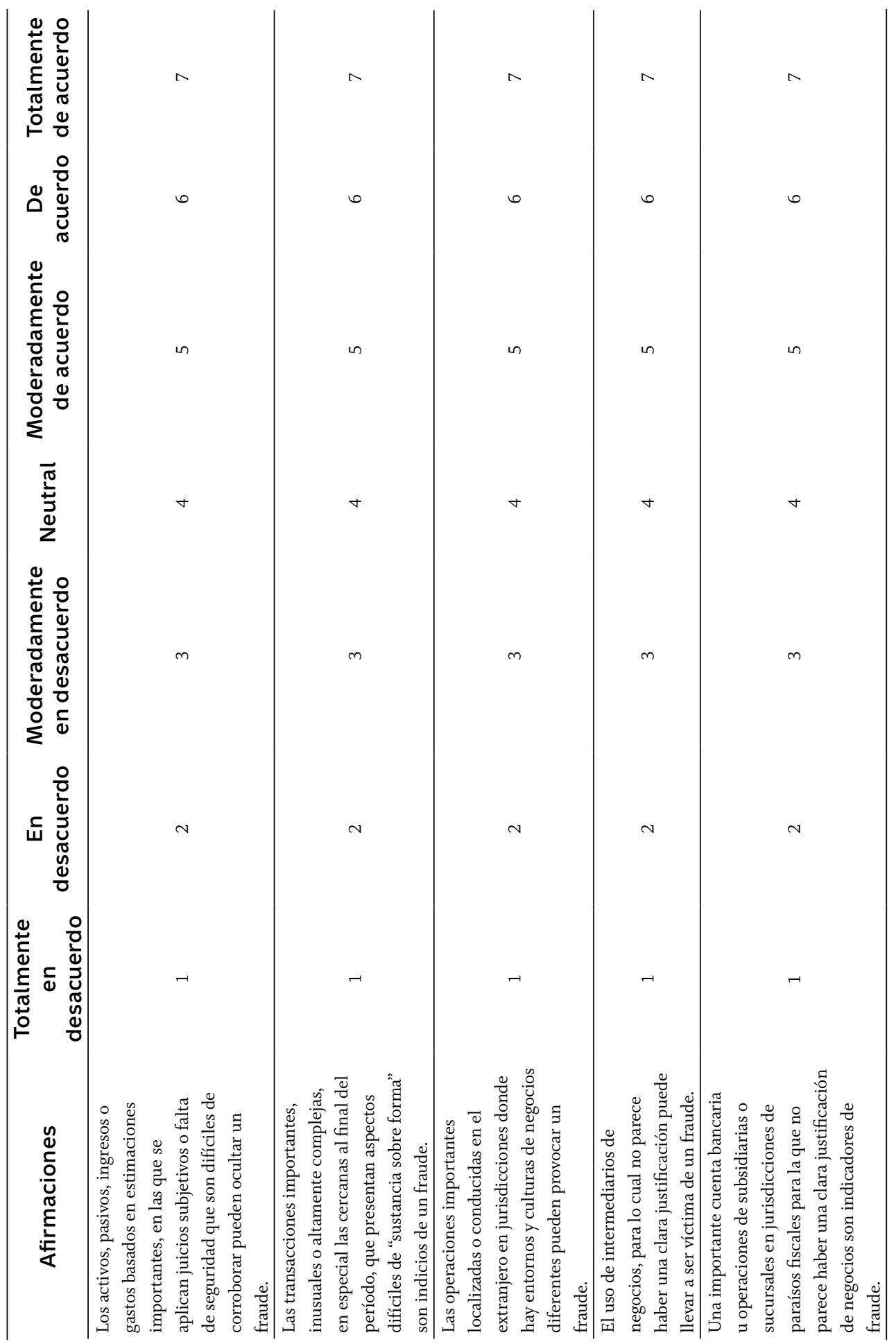


614 / VOL. 16/NO. 42 / SEPTIEMBRE-DICIEMBRE 2015

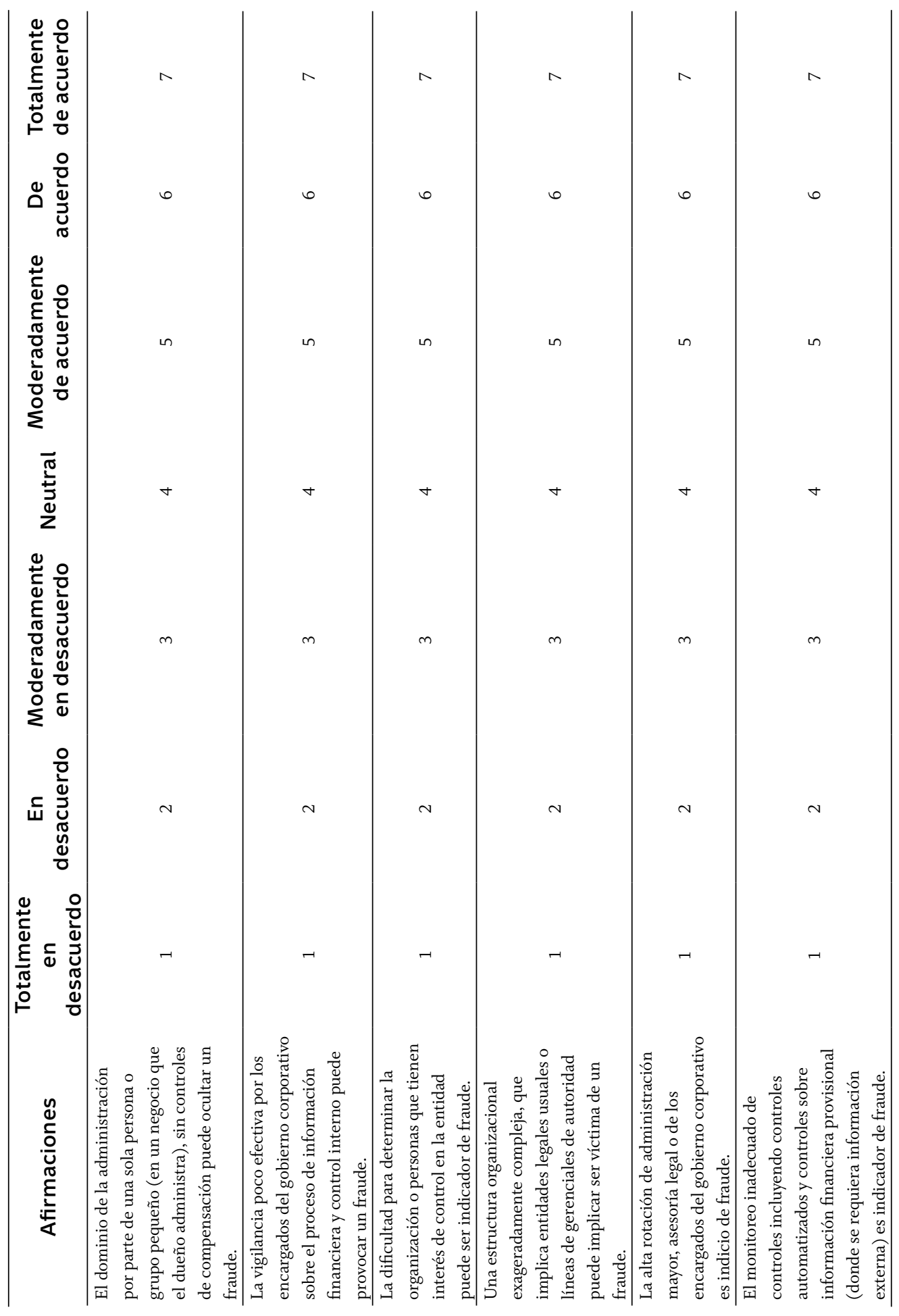


MODELO PROPUESTO PARA LA DETECCIÓN DE FRAUDES / J. SALAS-ÁVILA, N. REYES-MALDONADO / 615

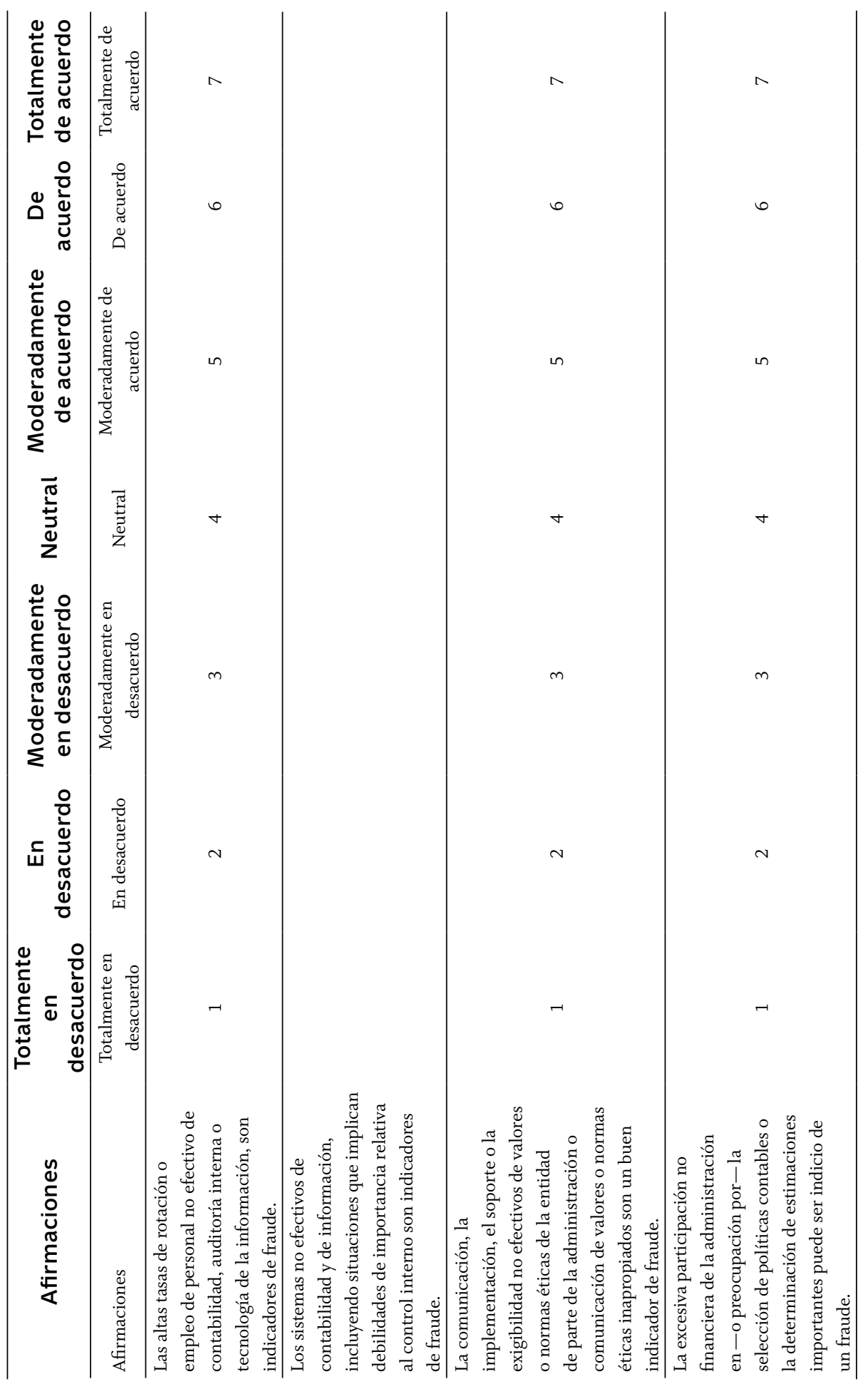


616 / VOL. 16 / NO. 42 / SEPTIEMBRE-DICIEMBRE 2015

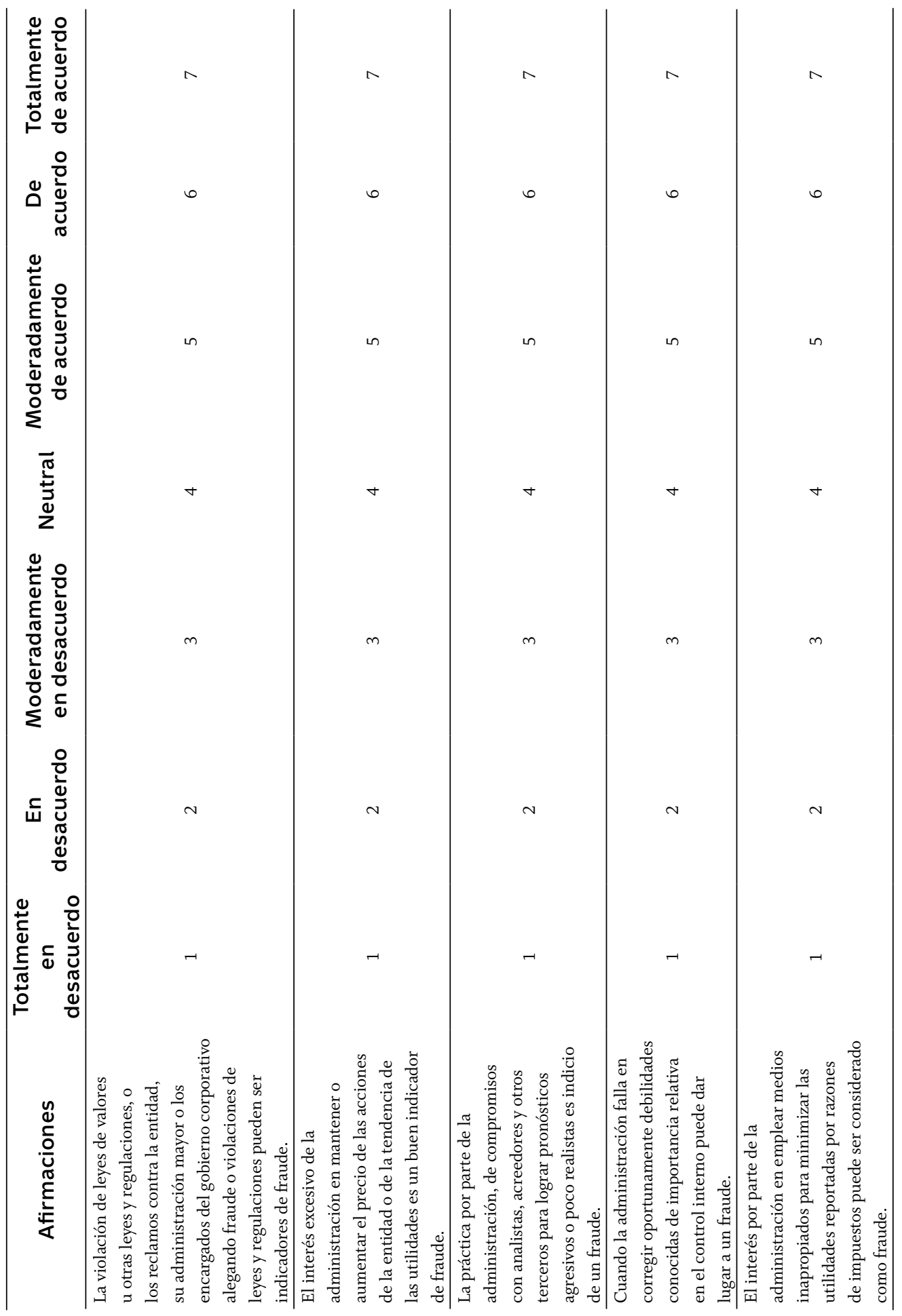


MODELO PROPUESTO PARA LA DETECCIÓN DE FRAUDES / J. SALAS-ÁVILA, N. REYES-MALDONADO / 617

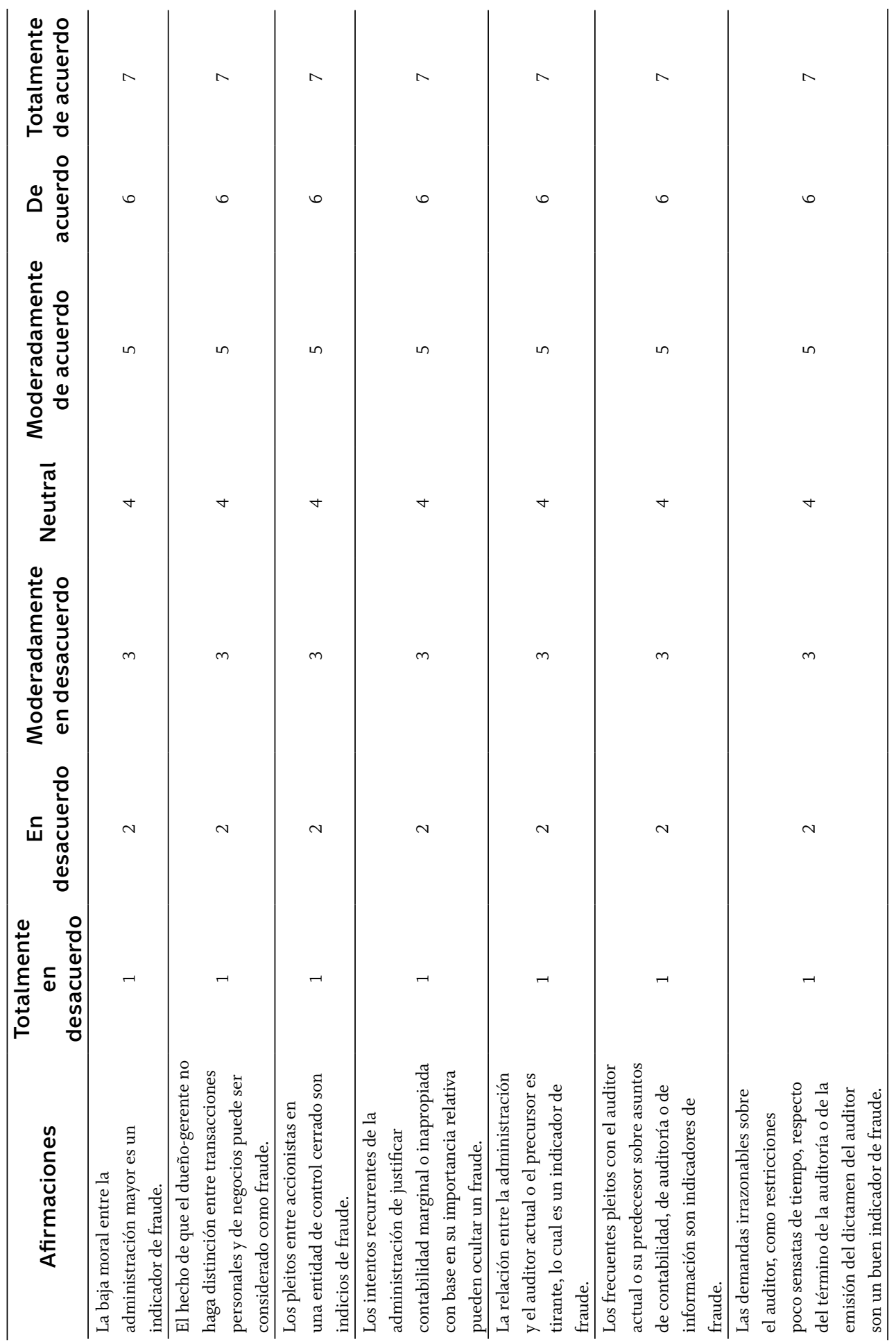


618 / VOL. 16 / NO. 42 / SEPTIEMBRE-DICIEMBRE 2015

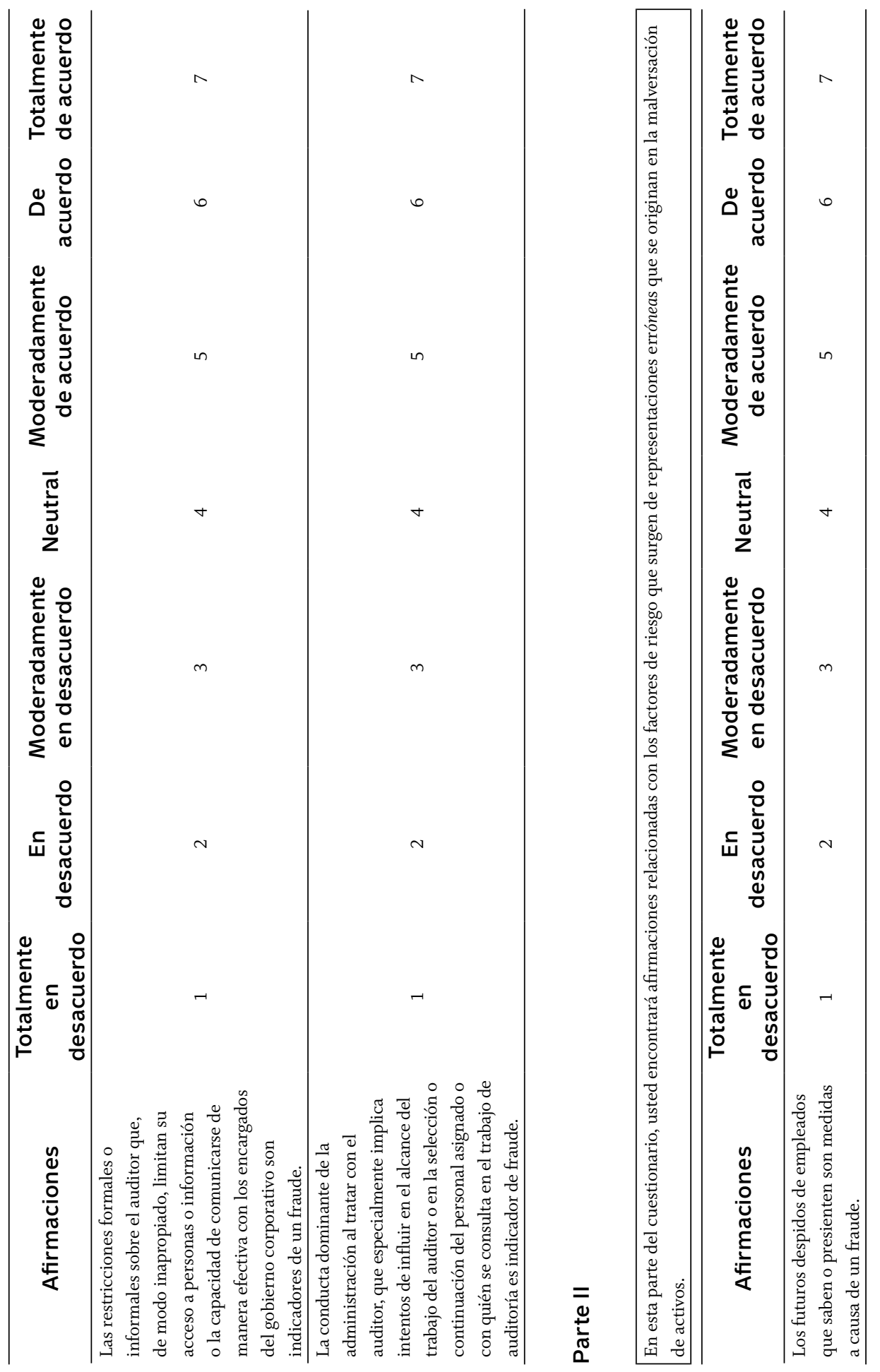




$$
[
$$


620 / VOL. 16 / NO. 42 / SEPTIEMBRE-DICIEMBRE 2015

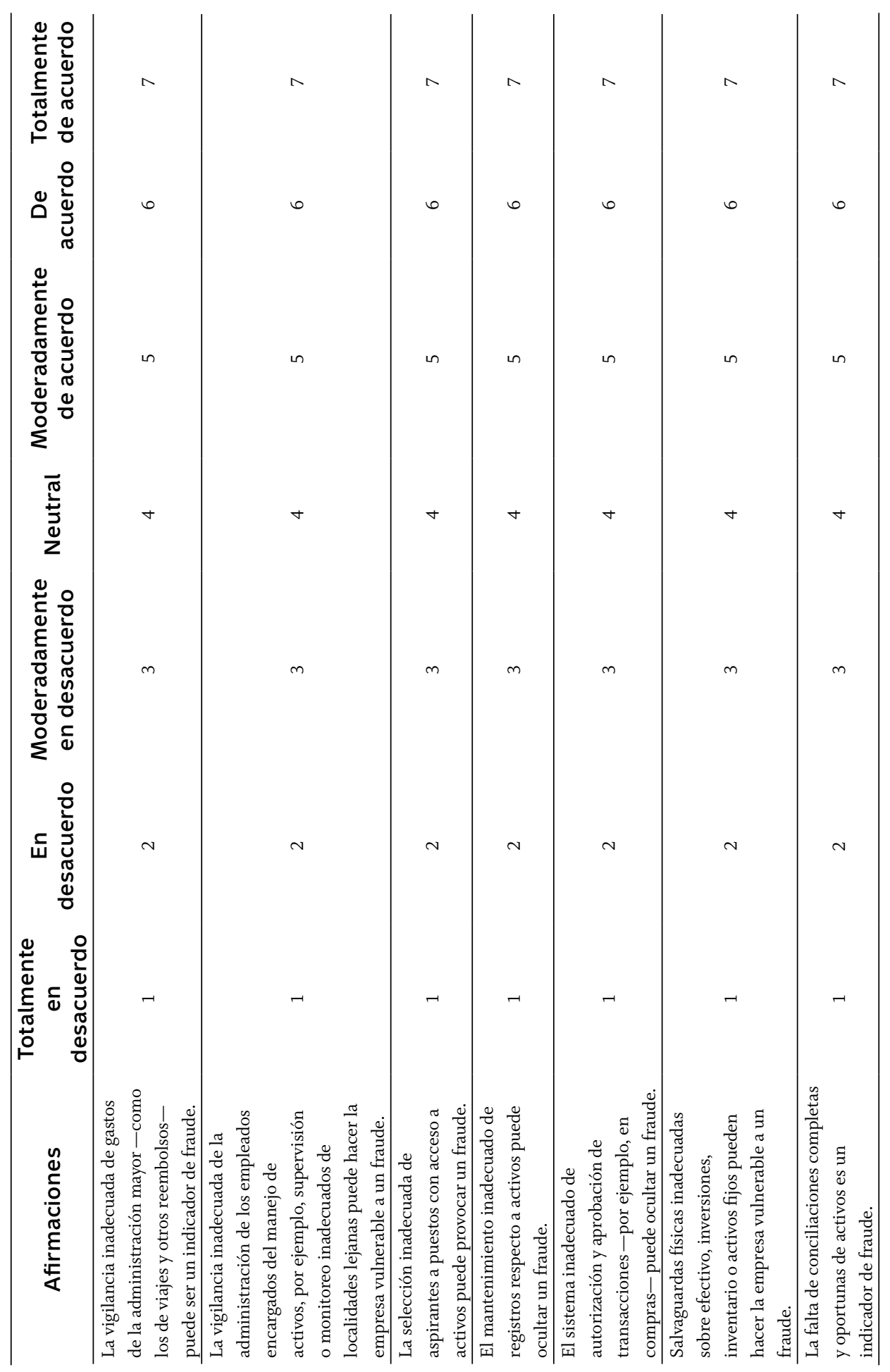




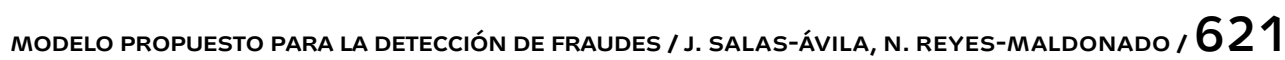

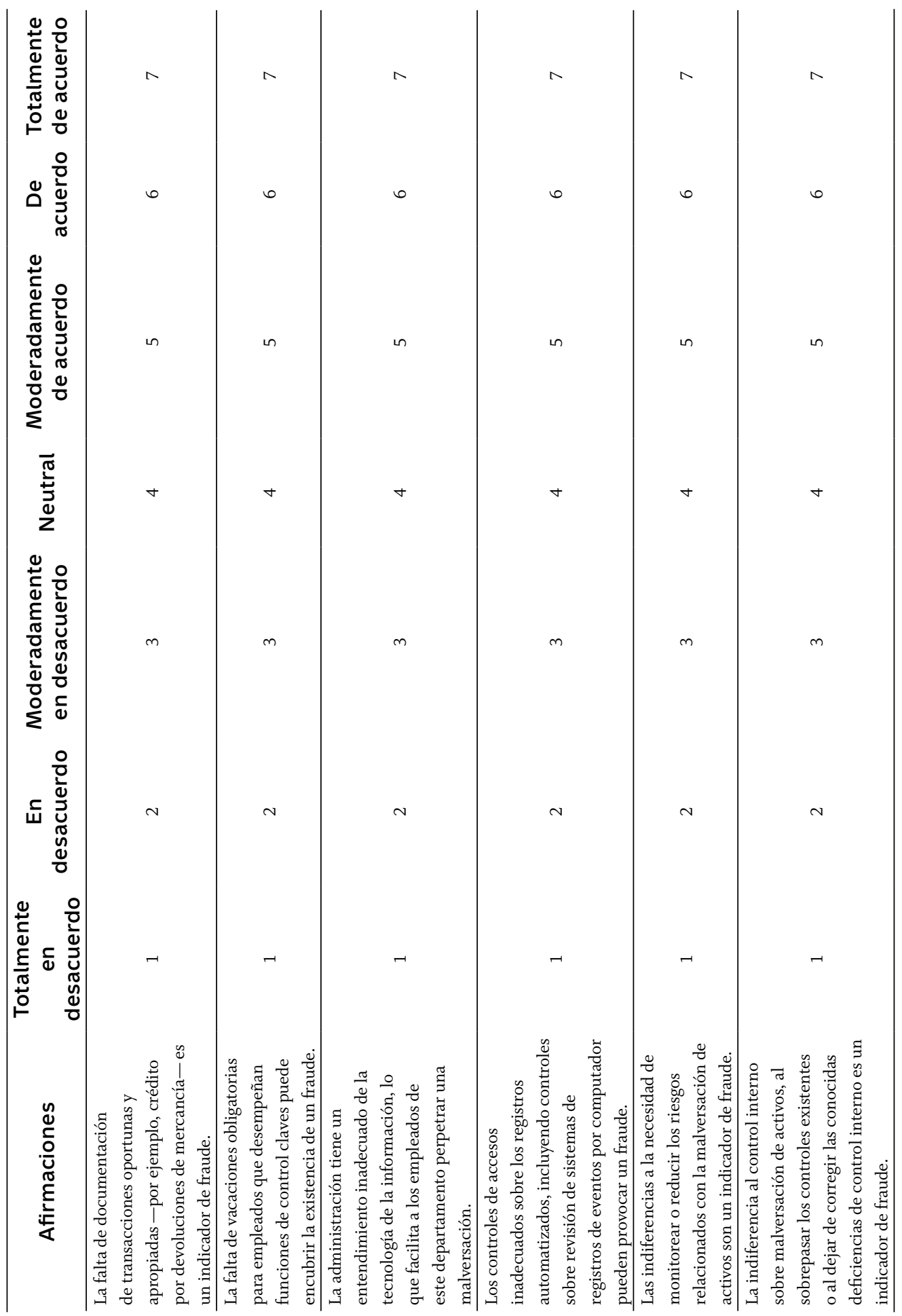


622 / VOL. 16/ NO. 42 / SEPTIEMBRE-DICIEMBRE 2015

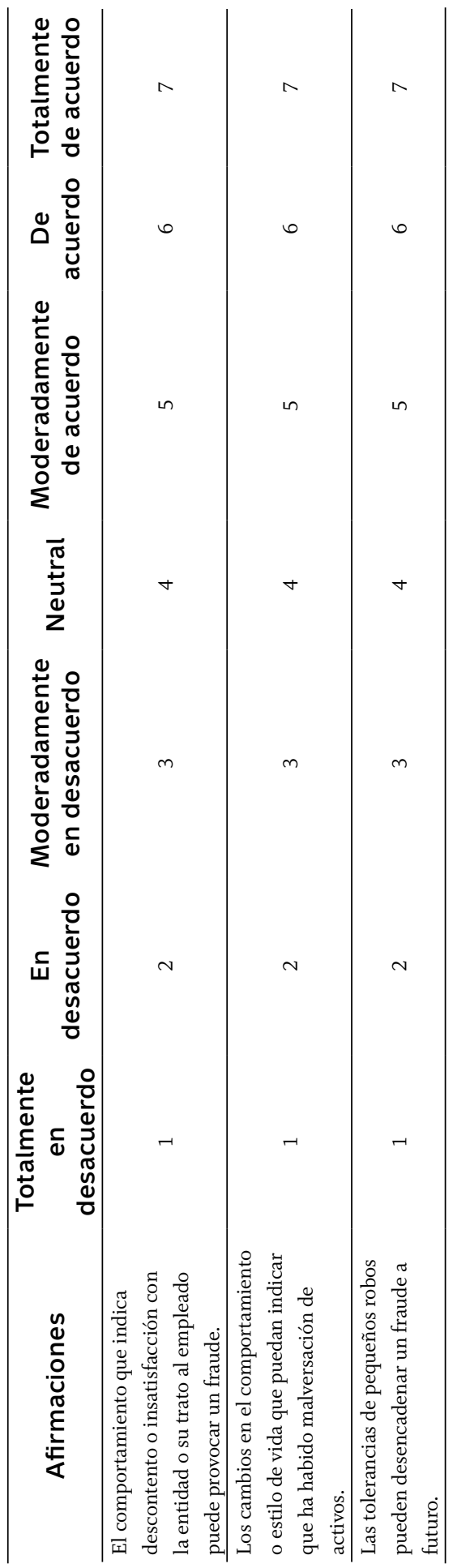


MODELO PROPUESTO PARA LA DETECCIÓN DE FRAUdes / J. SALAS-ÁVILA, N. REYES-MALDONAdo / 623

\section{Parte III}

Preguntas demográficas

En esta sección, por favor, indique la siguiente información acerca de usted mismo

1. País en donde trabaja: Argentina Chile México Perú Bolivia Otro Indicar:

2. Tipo de empresa: Listada internacional Listada nacional No listada Otro Indicar:

3. Sexo: $M \quad F$

4. Auditor: Interno I. S. Otro Indicar:

5. Posición: Staff Línea Contraloría Asistente

6. Edad: Menos de $25 \quad 26-30 \quad 31-35 \quad 36-45$ Más de 46

7. Años de trabajo: $\quad$ Menos de $3 \quad$ 4-6 $\quad$ 7-10 Más de 10

8. Título profesional CPA Ingeniero comercial Ingeniero informático Otro Indicar 
